Revista Brasileira de Cartografia

ISSN 1808-0936 | https://doi.org/10.14393/revbrascartogr

Sociedade Brasileira de Cartografia, Geodésia, Fotogrametria e Sensoriamento Remoto

\title{
Mapeamento da Vegetação da Caatinga a partir de Dados Ópticos de Observação da Terra - Oportunidades e Desafios
}

\section{Mapping Caatinga Vegetation using Optical Earth Observation Data - Opportunities and Challenges}

Khalil Ali Ganem ${ }^{1}$, Andeise Cerqueira Dutra ${ }^{2}$, Marceli Terra de Oliveira ${ }^{3}$, Ramon Morais de Freitas ${ }^{4}$, Rosana Cristina Grecchi ${ }^{5}$, Rita Marcia da Silva Pinto Vieira ${ }^{6}$, Egidio Arai ${ }^{7}$, Fabrício Brito Silva ${ }^{8}$, Claudia Bloisi Vaz Sampaio ${ }^{9}$, Valdete Duarte ${ }^{10}$ e Yosio Edemir Shimabukuro ${ }^{11}$

1 Instituto Nacional de Pesquisas Espaciais (INPE), Divisão de Observação da Terra e Geoinformática (DIOTG), São José dos Campos, SP, Brasil. E-mail: khalilganem@hotmail.com

ORCID: https://orcid.org/0000-0001-9126-7138

2 Instituto Nacional de Pesquisas Espaciais (INPE), Divisão de Observação da Terra e Geoinformática (DIOTG), São José dos Campos, SP, Brasil. E-mail: andeise.dutra@inpe.br

ORCID: https://orcid.org/0000-0002-4454-7732

3 Instituto Nacional de Pesquisas Espaciais (INPE), Divisão de Observação da Terra e Geoinformática (DIOTG), São José dos Campos,

SP, Brasil. E-mail: marceliterra@gmail.com

ORCID: https://orcid.org/0000-0001-6087-6344

4 Camargo-Schubert Engenharia Eólica, Curitiba, PR, Brasil. E-mail: ramon@camargo-schubert.com

ORCID: https://orcid.org/0000-0002-1397-0407

5 Pesquisadora Independente, 21020 Ranco, Itália. E-mail: rogrecchi@ hotmail.com

ORCID: https://orcid.org/0000-0002-4306-0332

6 Instituto Nacional de Pesquisas Espaciais (INPE), Divisão de Impactos, Adaptação e Vulnerabilidades (DIIAV), São José dos

Campos, SP, Brasil. E-mail: rita.marcia@inpe.br

ORCID: https://orcid.org/0000-0002-9857-3872

7 Instituto Nacional de Pesquisas Espaciais (INPE), Divisão de Observação da Terra e Geoinformática (DIOTG), São José dos Campos,

SP, Brasil. E-mail: egidio.arai@inpe.br

ORCID: https://orcid.org/0000-0003-1994-5277

8 Universidade CEUMA, Programa de Mestrado em Meio Ambiente, São Luís, MA, Brasil. E-mail: fabricio.brito@ceuma.br

ORCID: https://orcid.org/0000-0002-9878-0206

9 Universidade Federal do Recôncavo da Bahia (UFRB), Centro de Ciências Exatas e Tecnológicas (CETEC), Cruz das Almas, BA,

Brasil. E-mail: claudiabloisi@gmail.com

ORCID: https://orcid.org/0000-0003-1919-0900

10 Instituto Nacional de Pesquisas Espaciais (INPE), Divisão de Observação da Terra e Geoinformática (DIOTG), São José dos Campos, SP, Brasil. E-mail: valdete.duarte@inpe.br

ORCID: https://orcid.org/0000-0002-8016-7833

11 Instituto Nacional de Pesquisas Espaciais (INPE), Divisão de Observação da Terra e Geoinformática (DIOTG), São José dos

Campos, SP, Brasil. E-mail: yosio.shimabukuro@inpe.br

ORCID: https://orcid.org/0000-0002-1469-8433

Resumo: O bioma Caatinga representa cerca de $10 \%$ do território nacional e tem uma população estimada em 28 milhões de habitantes. Sua vegetação arbóreo-arbustiva, adaptada às condições de semiaridez, exerce um papel fundamental na manutenção do balanço hidrológico, na alimentação da matriz energética e na geração de receitas para o país. No entanto, o bioma ainda é um dos que recebe menor atenção da comunidade científica. Diante disso, o presente artigo de revisão visa apresentar elementos que contribuam para a atualização do estado da arte sobre o uso de dados ópticos de observação da Terra na conservação da vegetação da Caatinga, a partir da identificação das iniciativas de mapeamento em diferentes escalas que contemplam o bioma. Para tal, esse estudo fez uma revisão bibliográfica sistemática cujo enfoque principal foi a caracterização dos sensores orbitais imageadores, técnicas de classificação de imagem, legendas de uso e cobertura, estratégias de validação, e o intervalo temporal compreendido por cada iniciativa. Esse detalhamento permitiu avaliar o grau de usabilidade e confiabilidade dos produtos existentes. Assim, esse estudo espera abrir possibilidades para preencher lacunas científicas existentes e que carecem de 
investigação no que diz respeito ao papel dos dados ópticos de observação da Terra no mapeamento da vegetação da Caatinga e no subsídio de recursos para novas iniciativas, ações de restauração e, consequentemente, aprimoramento de políticas públicas em prol da conservação e uso sustentável dos recursos do bioma.

Palavras-chave: Sensoriamento Remoto. Florestas Tropicais Sazonalmente Secas. Semiárido. Cobertura da terra. Nordeste do Brasil.

\begin{abstract}
The Caatinga biome represents around $10 \%$ of the Brazilian territory, and it has an estimated population of 28 million inhabitants. Its tree-shrub vegetation, adapted to semi-arid conditions, plays a fundamental role in maintaining the hydrological balance, feeding the energy matrix, and generating revenues for Brazil. Despite its importance, the Caatinga is one of the most neglected biomes by the scientific community. Therefore, this review article aims to present elements that contribute to updating the state-of-the-art on the use of optical Earth observation data in the conservation of Caatinga vegetation, based on the identification of mapping initiatives at different scales that consider the biome. To this end, this study carried out a systematic bibliographic review in which the main focus was the characterization of orbital sensors, image classification techniques, land-use and land-cover classes, validation strategies, and the time interval defined by each mapping initiative. This detailed overview allowed us to assess the degree of usability and reliability of the existing products. Therefore, this study looks to open up possibilities to fill current scientific gaps that need further investigation regarding the role of optical Earth observation data in mapping the vegetation of the Caatinga and subsidizing resources for new initiatives, restoration actions, and hence the improvement of public policies favoring the conservation and sustainable use of the Caatinga's resources.
\end{abstract}

Keywords: Remote Sensing. Seasonally Dry Tropical Forests. Semiarid. Land-cover. Northeast Brazil.

\title{
1 INTRODUÇÃO
}

A Caatinga é o único bioma exclusivamente brasileiro e é considerada uma das maiores regiões de clima semiárido (MORO et al., 2016) e mais povoadas (RIBEIRO et al., 2016) do mundo, com uma população estimada em 28 milhões de habitantes. O bioma é rico em biodiversidade e no número de espécies endêmicas (SOBRINHO et al., 2016), mas é um dos menos estudados do Brasil pela comunidade científica (VELLOSO et al., 2002; SANTOS et al., 2011). Essa negligência é uma consequência provável do interesse da maioria dos estudos em mapear apenas florestas densas e úmidas. Enquanto isso, desmatamentos e queimadas ameaçam a Caatinga e fazem com que o bioma seja um dos mais sensíveis às mudanças climáticas, atingindo níveis críticos de vulnerabilidade.

Como resultado, tem-se prejuízos para a saúde humana, maior escassez hídrica, impactos econômicos de pequena e larga escala e aumento da desertificação. No entanto, a vegetação arbóreo-arbustiva da Caatinga adaptada às condições de semiaridez exerce um papel fundamental na manutenção do balanço hidrológico e na preservação dos recursos hídricos existentes. Além disso, as principais fontes que sustentam a economia da região Nordeste do Brasil provêm da vegetação da Caatinga, seja pela lenha que alimenta a matriz energética ou pelo recurso florestal não madeireiro utilizado para fabricar produtos que geram receitas para o país (PAREYN, 2010).

Uma consulta realizada em todos os bancos de dados da plataforma Web of Science em junho de 2020 indicou que a Caatinga é 73\% menos estudada que a Amazônia, 68\% menos que o Cerrado e 65\% menos que a Mata Atlântica. Além disso, grande parte dos programas institucionais de mapeamento em escala de bioma estão voltados para a Amazônia, Mata Atlântica e, mais recentemente, Cerrado, com pouco investimento técnico-científico em favor da Caatinga. Isso ressalta a importância de se aumentar os esforços científicos em prol do preenchimento das lacunas existentes para a produção de informações mais acuradas e atualizadas sobre o status de conservação da vegetação da Caatinga no âmbito do Sensoriamento Remoto.

Assim, o presente estudo tem como objetivo enriquecer essas discussões a partir da identificação das iniciativas de mapeamento já realizadas no bioma, da caracterização das técnicas de classificação empregadas e da descrição dos sensores orbitais imageadores utilizados. Também foi analisado o intervalo temporal, as legendas de uso e cobertura da terra e as estratégias de validação adotadas por essas iniciativas, bem como o nível de acurácia obtido. Para alcançar esse objetivo, foi feita uma revisão bibliográfica sistemática, na qual foram avaliados periódicos nacionais e internacionais e não houve intervalo temporal pré-definido para a filtragem dos estudos. A compilação dessas informações permitiu atualizar o estado da arte sobre o mapeamento da vegetação da Caatinga no âmbito dos dados ópticos de observação da Terra. 


\section{CAATINGA: UM BIOMA EXCLUSIVAMENTE BRASILEIRO}

O termo caatinga é de origem tupi-guarani e significa "mata branca", devido ao aspecto seco e esbranquiçado da paisagem quando as folhas caem no período de estiagem (ALBUQUERQUE; BANDEIRA, 1995). Sob um ponto de vista mais abrangente, a Caatinga faz parte de um outro bioma global, denominado florestas tropicais sazonalmente secas (ALBUQUERQUE et al., 2012; BRITO; PRESLEY; SANTOS, 2012), sendo a área mais vasta e contínua desse grupo que situa-se na América do Sul (SANTOS et al., 2012).

No Brasil, muitas vezes o termo Semiárido é utilizado em referência à Caatinga. No entanto, faz-se necessário esclarecer que, no contexto brasileiro, o Semiárido se refere a uma região delimitada pela Superintendência de Desenvolvimento do Nordeste (SUDENE), que ocupa aproximadamente 12\% do território nacional, equivalente a $1.128 .697 \mathrm{~km}^{2}$, e abrange 1.262 municípios brasileiros (BRASIL, 2017a). Para que um município da área de atuação da SUDENE seja considerado apto para a inclusão no Semiárido, ele deve alcançar pelo menos um dos três critérios técnico-científicos a seguir (BRASIL, 2017b, p.1):

I - precipitação pluviométrica média anual igual ou inferior a $800 \mathrm{~mm}$;

II - índice de aridez de Thornthwaite igual ou inferior a 0,50 ;

III - percentual diário de déficit hídrico igual ou superior a $60 \%$, considerando todos os dias do ano.

A maior parte do Semiárido situa-se na região Nordeste do Brasil (NEB), se estendendo também para Minas Gerais, onde ocupa aproximadamente $18 \%$ da área total do estado. Além disso, no Semiárido também ocorre outro bioma brasileiro: o Cerrado. Portanto, é importante destacar que o Semiárido é uma delimitação política, definida com base em parâmetros climatológicos, ao passo que a Caatinga é um bioma, determinado pelo seu tipo de vegetação predominante. A Figura 1 mostra o mapa da localização e dos limites da Caatinga e do Semiárido, assim como os estados que ambos abrangem. É necessário destacar que foram considerados os novos limites do bioma definidos pelo Instituto Brasileiro de Geografia e Estatística (IBGE, 2019) para a criação desse mapa.

Figura 1 - Mapa de delimitação dos limites da região Nordeste, do Semiárido brasileiro e do bioma Caatinga, bem

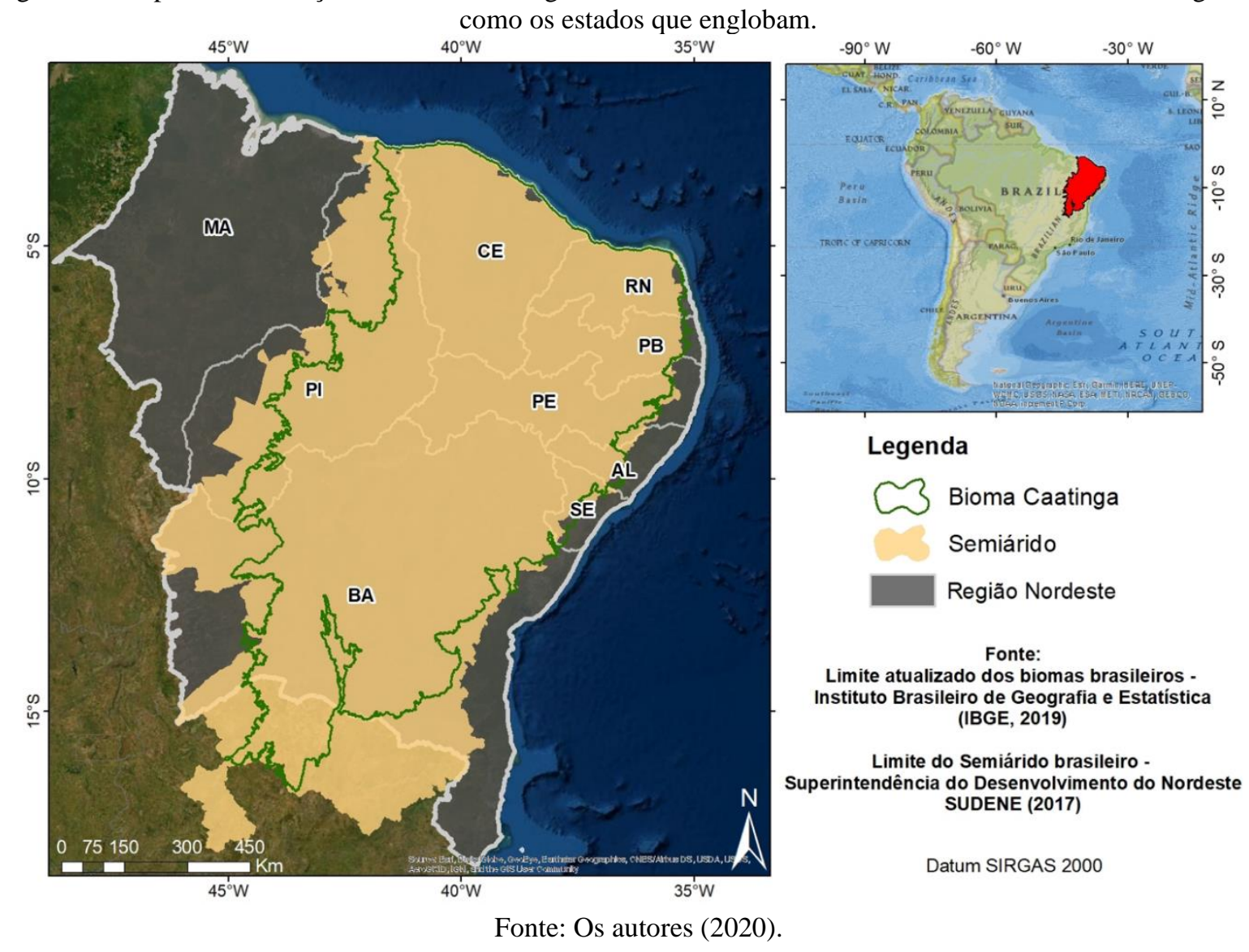


A área total da Caatinga é de $862.818 \mathrm{~km}^{2}$ (IBGE, 2019), o que corresponde a aproximadamente $10 \%$ do território do Brasil. A Caatinga é cercada pelos biomas Mata Atlântica e Cerrado, e representa 54\% do NEB, englobando 100\% do estado do Ceará (CE) e parte dos estados de Alagoas (AL), Bahia (BA), Maranhão (MA), Paraíba (PB), Pernambuco (PE), Piauí (PI), Rio Grande do Norte (RN) e Sergipe (SE). Além disso, o bioma também está presente em parte do estado de Minas Gerais (MG), na região Sudeste brasileira.

Em termos climatológicos, há uma predominância do clima semiárido na Caatinga (ALVARES et al., 2013) e os índices pluviométricos são baixos, variando de 250 a $900 \mathrm{~mm}$ por ano (ALVES; ARAÚJO; NASCIMENTO, 2009). Há ainda uma grande variabilidade espaço-temporal na ocorrência de chuvas no bioma (MARENGO; TORRES; ALVES, 2017), o que implica em longos períodos de seca, com duração de seis a onze meses dependendo do local (MORO et al., 2016).

A localização entre o Equador e o Trópico de Capricórnio expõe a Caatinga a uma elevada radiação solar durante todo o ano (MORO et al., 2016). Por isso, a temperatura média varia entre $25^{\circ} \mathrm{C}$ e $30^{\circ} \mathrm{C}$ e não há muita diferença entre os meses de inverno e verão. Em períodos de chuva, a água que precipita não é armazenada pelo solo pedregoso, o que explica as altas taxas de evapotranspiração (GANEM, 2017). Já a umidade relativa, é baixa, com valores próximos a $50 \%$.

\subsection{Dinâmicas de Uso e Ocupação da terra}

Uma porção considerável da vegetação nativa da Caatinga foi fortemente alterada por impactos antrópicos (LEAL et al., 2003). Historicamente, a degradação do bioma pode ser explicada pelo processo de ocupação do Nordeste brasileiro, que se iniciou no litoral e avançou para o interior com a intensificação da extração de recursos naturais e produção agrícola para fins de exportação (ALVES; ARAÚJO; NASCIMENTO, 2009). A partir do século XVII, a criação de gado se iniciou nas fazendas e os primeiros núcleos urbanos começaram a surgir.

Um traço característico do antropismo na Caatinga é a fragmentação da paisagem por atividades agrícolas - cerca de $75 \%$ das propriedades agrícolas possuem menos de 10 hectares (REDO; AIDE; CLARK, 2013). Esse padrão não é facilmente detectável por sensores de baixa a moderada resolução espacial, o que justifica o uso de sensores de alta resolução (LAMBIN; GEIST; LEPERS, 2003; STROPPIANA et al., 2012). Mesmo fragmentadas, as atividades agrícolas têm apresentado um declínio nas últimas décadas, conforme apontado por Redo, Aide e Clark (2013). De acordo com os autores, essa queda foi influenciada principalmente pela perda da competitividade econômica de cultivos (como o algodão), longos períodos de seca, movimentos de êxodo rural, além do elevado custo da mão-de-obra no campo.

Atualmente, a pecuária é a principal atividade econômica da Caatinga. Por exemplo, a área de pastagem plantada do bioma equivalia a aproximadamente $210 \mathrm{mil} \mathrm{km}^{2} \mathrm{em} \mathrm{2018}$, ou seja, mais de $25 \%$ de sua área total (MAPBIOMAS, 2020). Isso ocorre porque a vegetação nativa permite um consumo de matéria seca capaz de atender às necessidades dos animais (ALVES; ARAÚJO; NASCIMENTO, 2009). Giulietti et al. (2004) apontaram que uma área considerável da Caatinga é designada para pastagens nativas em todos os estados, com exceção da porção norte de Minas Gerais. Os autores também acrescentaram que essas pastagens são mais diversas que as pastagens plantadas, além de serem uma alternativa para conciliar uso e manutenção da biodiversidade.

Albuquerque (1999) afirmou que a degradação na Caatinga nem sempre é diretamente de origem antrópica, devendo o clima também ser levado em consideração. O clima exerce um papel fundamental nas dinâmicas de uso da terra e na evolução da paisagem do bioma (MALDONADO; SANTOS; CARVALHO, 2002). Especificamente na Caatinga, alguns estudos apontam a desertificação como uma das principais ameaças impostas pelas mudanças de uso e cobertura da terra (WAN et al., 2004; VIEIRA et al., 2015; TOMASELLA et al., 2018).

\subsection{Características da Vegetação da Caatinga}

Ao longo das últimas décadas, algumas classificações foram propostas para os diferentes tipos de vegetação existentes na Caatinga (ANDRADE-LIMA 1981; VELOSO; GÓES FILHO, 1982; EITEN, 1983; 
CHAVES et al., 2008; CAVALCANTI, 2018). O bioma possui espécies vegetais adaptadas ao déficit hídrico típico do clima semiárido da região, o que é evidenciado pela predominância de arbustos e árvores de pequeno porte, cuja principal característica é a deciduidade na estação seca (FERNANDES; QUEIROZ, 2018). Além disso, para melhor se adaptarem às condições climáticas mais extremas, as plantas geralmente possuem folhas finas, pequenas e espinhosas. No entanto, isso não isenta a Caatinga de possuir espécies vegetais que podem ser altamente vulneráveis a rápidas mudanças climáticas (ALBUQUERQUE et al., 2012).

Algumas plantas armazenam água, como os cactos, e outras apresentam raízes praticamente na superfície do solo para absorver o máximo da chuva. Como a disponibilidade de água limita o desenvolvimento e o ciclo de vida das plantas, o comportamento fenológico da vegetação é fortemente influenciado pelo regime de chuvas, mesmo durando pouco (LIMA; RODAL, 2010; ERASMI et al., 2014). As folhas aparecem rapidamente e as plantas completam seus ciclos reprodutivos em um curto período.

A estrutura da vegetação da Caatinga é bastante heterogênea (RODAL; BARBOSA; THOMAS, 2008), apresentando trechos de vegetação arbórea que formam um dossel contínuo, árvores baixas e esparsas, e um estrato arbustivo mais denso (xerófilas). Os padrões de distribuição da vegetação ao longo do bioma, inclusive, foram levados em consideração por Velloso et al. (2002) ao definirem oito ecorregiões para a Caatinga. No bioma, há três diferentes estratos vegetais típicos (ALVES; ARAÚJO; NASCIMENTO, 2009): arbóreo (8 a 12 metros), arbustivo ( 2 a 5 metros) e herbáceo (abaixo de 2 metros). A Figura 2 apresenta as fitofisionomias mais encontradas da Caatinga, com base na definição do Manual Técnico da Vegetação Brasileira (IBGE, 2012).

Figura 2 - Principais Fitofisionomias da Caatinga

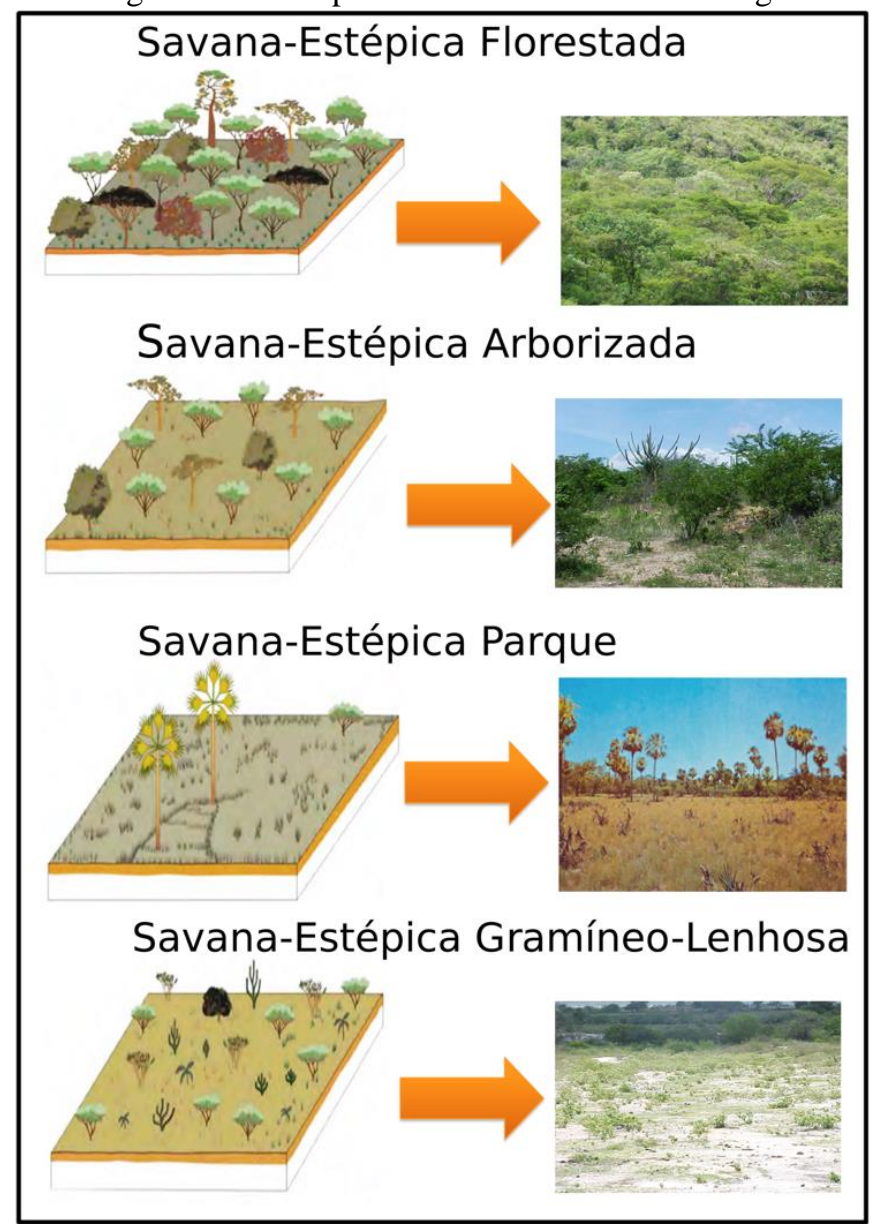

Fonte: Adaptada de IBGE (2012) e MapBiomas (2020) - equipe Caatinga.

$\mathrm{Na}$ Caatinga, o tipo de vegetação predominante é a savana-estépica. De acordo com o Manual Técnico da Vegetação Brasileira do IBGE (2012), a savana-estépica florestada é formada por um estrato superior que pode ser muito ou pouco adensado e um estrato inferior gramíneo-lenhoso, geralmente descontínuo e pouco expressivo em termos de fisionomia. A savana-estépica arborizada é composta por um estrato arbustivo- 
arbóreo superior e esparso, e um estrato inferior gramíneo-lenhoso, de relevante importância fitofisionômica (IBGE, 2012). A savana-estépica parque é caracterizada por arbustos e pequenas árvores, geralmente da mesma espécie, e com uma distribuição bastante espaçada. Por fim, a savana-estépica gramíneo-lenhosa é distinta por um extenso tapete graminoso.

\subsection{Análise Bibliográfica: A Vegetação da Caatinga na Literatura}

Uma pesquisa realizada em 27 de junho de 2020 em todas as bases de dados da plataforma Web of Science (WoS) e sem intervalo temporal pré-definido retornou 3.414 artigos para o termo "Caatinga". Uma segunda pesquisa utilizando a expressão "drylands AND Brazil" retornou 61 artigos. Essa expressão também foi usada para abranger artigos da literatura internacional que se referem ao bioma sem usar seu nome. Mesmo o WoS limitando o número de exportações em 500 por arquivo, toda a base de dados foi extraída para então ser feita uma análise da co-ocorrência de palavras importantes nos títulos e resumos de cada artigo. Isso foi feito por meio do VOSviewer (VAN ECK; WALTMAN, 2010), um software voltado para a construção e visualização de redes bibliométricas.

Para a análise de co-ocorrência, foi utilizado um método de contagem binário, o que significa que o número de vezes que um determinado termo ocorreu em um mesmo artigo foi desconsiderado. Foram identificados mais de 14.000 termos, e, por isso, definiu-se uma quantidade mínima de 50 ocorrências por termo. Dentre as maiores ocorrências, constam nomenclaturas específicas da ecologia, termos triviais ("study", "region", etc.) e a palavra "vegetation", com 496 registros. Por se tratar de um termo que se relaciona ao tema central do presente artigo, a palavra foi utilizada para refinar a primeira pesquisa no WoS, o que resultou em 1.011 artigos que abordam a vegetação da Caatinga.

A taxa de publicação desse conjunto de artigos variou pouco até o fim da década de 90 . O primeiro foi publicado em 1960 e a publicação do segundo se deu após uma lacuna de 10 anos, já na década de 70, na qual apenas cinco artigos foram publicados. Na década de 80, a média de publicação foi de 2 artigos por ano, quantidade essa que dobrou na década de 90 . No início do século XXI, nota-se um aumento mais expressivo da taxa de publicação, com um crescimento súbito em meados de 2010, conforme demonstra a Figura 3.

Figura 3 - Número de artigos (valor cumulativo) retornados após pesquisa pela expressão "Caatinga AND vegetation" na plataforma Web of Science em 27 de junho de 2020.

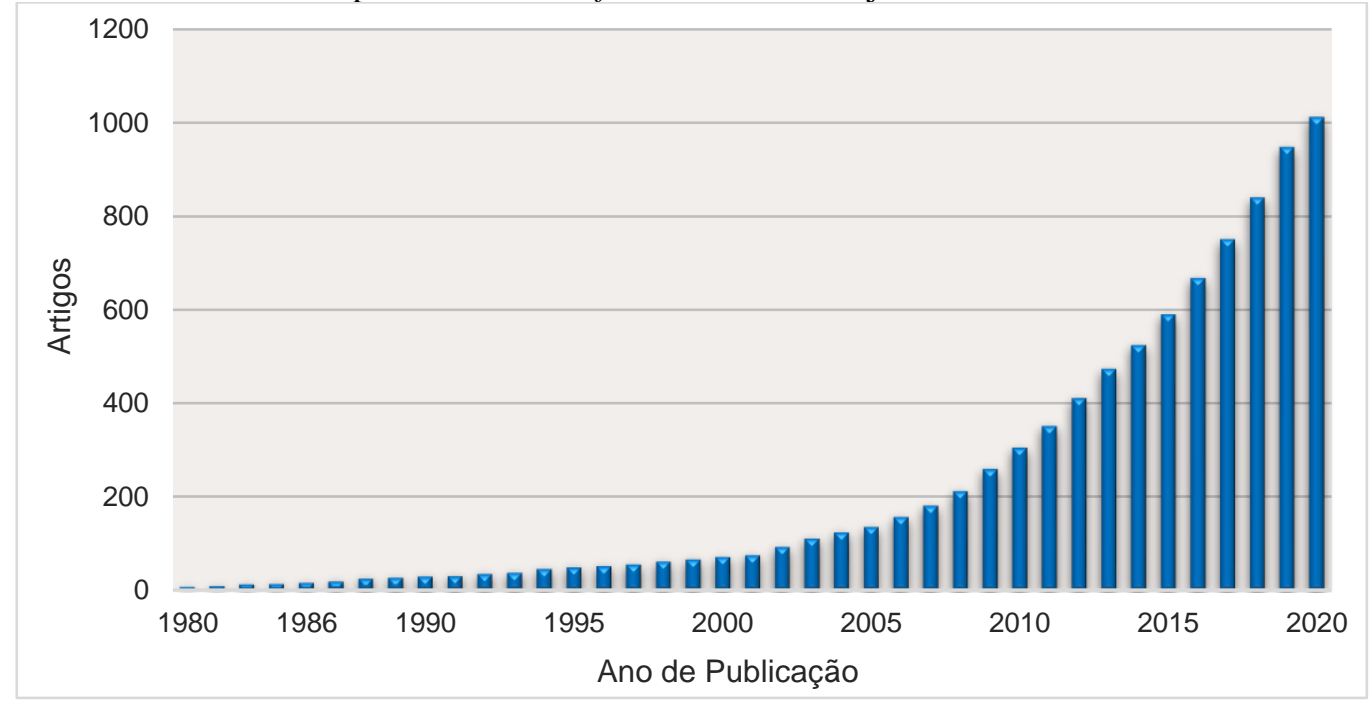

Fonte: Os autores (2020).

Uma parcela significativa dos artigos publicados $(91,8 \%)$ está associada a instituições brasileiras. O restante conta com a contribuição incipiente (menos que 10\%), mas não menos importante, de instituições de países como Estados Unidos, Alemanha, Inglaterra, Argentina, Austrália, México e Holanda. A nível nacional, a maior parte dos artigos são liderados por instituições situadas em estados inseridos nos limites da Caatinga, com Pernambuco liderando o número de publicações, seguido da Paraíba, Ceará, Bahia e Rio Grande do Norte. 
Na base de dados identificada para a vegetação da Caatinga, alguns artigos que utilizaram dados de observação da Terra merecem destaque pela abordagem recente a nível de bioma. Redo, Aide e Clark (2013) mapearam as mudanças na cobertura da terra da Caatinga e de outros ecossistemas similares utilizando dados do sensor Moderate Resolution Imaging Spectroradiometer (MODIS) no período de 2001 a 2009. Beuchle et al. (2015) se basearam nas funções de associação definidas por uma coleção de assinaturas espectrais (RAŠI et al., 2011; RAŠI et al., 2013) para desempenhar a classificação orientada a objeto em imagens da série Landsat (TM, ETM+) em três períodos: 1990, 2000 e 2010. Outro conjunto de artigos encontrados na literatura que utilizaram dados de observação da Terra na Caatinga estão relacionados ao uso de dados multitemporais de índices de vegetação para estudos da variabilidade da fenologia em relação à precipitação e períodos de secas extremas (BARBOSA; HUETE; BAETHGEN, 2006; BARBOSA; KUMAR, 2016; BARBOSA et al., 2019).

Já Shimabukuro et al. (2020) desenvolveram um método para discriminar sete classes de uso e cobertura da terra em todos os biomas brasileiros para o ano de 2015, a partir da aplicação do Modelo Linear de Mistura Espectral (MLME) em dados do sensor Vegetation a bordo do satélite Project for On-Board Autonomy (PROBA-V). Além da abordagem a nível de bioma, estudos a nível estadual ou em pequenas áreas dentro do bioma também podem ser encontrados. Na Bahia, Dutra (2019) classificou a vegetação utilizando imagens intranuais e a técnica Random Forest, além de aplicar o MLME em imagens do MODIS entre 2000 e 2017 como alternativa para o monitoramento do uso e cobertura da terra no estado.

Mais recentemente, Cunha et al. (2020) investigaram padrões espaço-temporais de remoção da cobertura vegetal em uma área da Caatinga situada no estado da Paraíba. Os autores utilizaram dados Landsat (TM, ETM+ e OLI) em um intervalo de 31 anos (1985-2015) e compararam os índices espectrais Enhanced Vegetation Index (EVI), Normalized Difference Vegetation Index (NDVI) e albedo de superfície, tendo o último apresentado a melhor acurácia. Em uma área de Pernambuco, Santos et al. (2020) classificaram o uso e cobertura da terra utilizando a técnica de máxima verossimilhança em dados Landsat de 2007 e 2017 . Por fim, Silveira et al. (2018) combinaram pela primeira vez a classificação das fitofisionomias da Caatinga com atributos físico-químicos do solo usando dados do Sentinel-2 e LiDAR.

\section{INICIATIVAS DE MAPEAMENTO DA VEGETAÇÃO DA CAATINGA}

No último século, os dados cartográficos sobre a vegetação da Caatinga só haviam sido produzidos em escala de bioma pelo projeto RADAMBRASIL. No entanto, essa iniciativa não fez uso de dados ópticos, mas de radar, no período de 1975 a 1985 (IBGE, 2018). Devido ao processo de interiorização acelerado do território brasileiro nas últimas décadas do século XX, os mapas de vegetação do RADAMBRASIL já não refletiam a realidade (MMA, 2020). A fim de preencher essa lacuna, já no século XXI, o Ministério do Meio Ambiente (MMA) lançou editais para selecionar subprojetos de mapeamento da cobertura vegetal dos biomas brasileiros por meio do Projeto de Conservação e Utilização Sustentável da Diversidade Biológica Brasileira (PROBIO). Com isso, o mapeamento da Caatinga foi executado de setembro/2004 a setembro/2006, utilizando 2002 como ano base, e os dados oficiais foram lançados em 2007 (MMA, 2006).

Na sequência, a Secretaria de Biodiversidade e Florestas do Ministério do Meio Ambiente promoveu o Programa de Monitoramento do Desmatamento dos Biomas Brasileiros por Satélite (PMDBBS). Em março de 2011 foram lançados os primeiros mapeamentos dos remanescentes de vegetação para a Caatinga até o ano de 2002, e entre 2002 e 2008 (MMA/IBAMA, 2011). Nos anos seguintes, o PMDBBS divulgou atualizações dos dados de mapeamento de 2009, 2010 e 2011. Cabe enfatizar que os dados do mapeamento do PMDBBS são de desmatamento acumulado, isto é, englobam desmatamentos anteriores ao período mapeado. Para a Caatinga, esse mapeamento apresentou acurácia de $74 \%$.

Pouco tempo depois da divulgação dos primeiros dados do PMDBBS, Vieira et al. (2013) desenvolveram um mapa da distribuição espacial dos principais tipos de vegetação da região Nordeste para posterior uso em modelos meteorológicos e climáticos. Essa iniciativa foi nomeada ProVeg-NEB e se desenvolveu dentro do contexto do Projeto de Vegetação (ProVeg), cujo mapeamento inicial englobava apenas a região da Amazônia Legal (SESTINI et al., 2002). A metodologia desse mapeamento se baseou em duas etapas: a correspondência entre as classes do projeto RADAMBRASIL, do IBGE e do modelo Simplified 
Simple Biosphere (SSiB) (XUE et al., 1991), e o mapeamento do uso e cobertura da terra. O mapa final, que teve 2000 como ano de referência, foi construído a partir de um mosaico de imagens da série Landsat de 1999, 2000 e 2001. Dois anos depois, Vieira et al. (2015) atualizaram esse mapa para o ano de 2010, o qual foi utilizado juntamente com o mapa de 2000 na identificação de áreas susceptíveis a desertificação. Nessa atualização, o mapeamento do PROBIO e as imagens do Google Earth foram utilizados como dados auxiliares.

Em 2015, surgiu o Projeto de Mapeamento Anual da Cobertura e Uso do Solo no Brasil (MapBiomas), uma iniciativa formada por um conjunto de universidades, ONGs e empresas privadas que se uniram para gerar uma série histórica de mais de 30 anos de dados de mapeamento do uso e cobertura da terra para todos os biomas brasileiros (MAPBIOMAS, 2020). A partir de 2016, o MapBiomas passou a lançar uma coleção principal por ano, cada uma com versões mais aperfeiçoadas da metodologia de processamento, incluindo o ano mais recente e ampliando o intervalo temporal. A acurácia global da coleção 4.1 para cada ano da série temporal (1985 - 2018) é de $80 \%$ para a legenda de nível 1 e $75 \%$ para a legenda de nível 3. Atualmente, o MapBiomas apresenta a maior acurácia dentre os mapeamentos realizados para a Caatinga a nível de bioma, além de possuir o maior intervalo temporal mapeado.

Mais recentemente, o projeto "Monitoramento Ambiental dos Biomas Brasileiros por Satélites: Mata Atlântica, Caatinga, Pampa e Pantanal", com financiamento do Fundo Amazônia, executado pela Fundação de Ciência, Aplicações e Tecnologia Espaciais (FUNCATE) e sob coordenação técnica do Instituto Nacional de Pesquisas Espaciais (INPE), foi concebido para atender ao Programa de Monitoramento Ambiental dos Biomas Brasileiros (PMABB). Para a Caatinga, o projeto ainda se encontra em fase de execução e construirá uma série histórica de mapas de desmatamento bienais para o período de 2000 a 2012 para apoiar a construção de proposta para o Forest Reference Emission Level (FREL) do bioma (FUNDO AMAZÔNIA, 2020). Primeiramente, será construído o mapa do desmatamento do ano 2000 (mapa-base), e, posteriormente, serão produzidos mapas de incremento para cada biênio, compatíveis com o mapa-base. Paralelamente à construção do FREL, o mapeamento será gerado a partir de um conjunto de imagens do satélite Landsat- 8 ou similares para o monitoramento do desmatamento no período de 2013 a 2020, cobrindo toda extensão da Caatinga.

A nível estadual, os estudos se concentram em Pernambuco e Bahia, com os demais estados ainda carentes de iniciativas para mapear suas porções de Caatinga. Em Pernambuco, o mapeamento desenvolvido por Accioly et al. (2017) abrangeu o Semiárido do estado, com área total de $86.135 \mathrm{~km}^{2}$. Os autores utilizaram cartas topográficas na escala 1:100.000 e a avaliação da classificação foi feita qualitativamente por meio de viagens de campo. Na Bahia, em 2019, o Instituto do Meio Ambiente e Recursos Hídricos (INEMA) lançou um mapeamento da cobertura vegetal do estado a partir de classificação supervisionada e edição manual por interpretação visual do mosaico de imagens RapidEye (CONSÓRCIO GEOBAHIA, 2018). Esse mapeamento foi validado por expedições de campo e foram utilizadas cartas na escala de 1:50.000 como referência. Ao final, uma base contínua do bioma foi elaborada respeitando o enquadramento da folha ao milionésimo (1:100.000).

Sob uma perspectiva global, o Global Land Cover 2000 (GLC2000) foi criado a partir de uma parceria do Joint Research Centre (JRC) da Comissão Europeia com uma rede de colaboradores do mundo todo para produzir um mapa harmonizado da cobertura da terra para o ano 2000, a partir de uma resolução espacial de 1 km (BARTHOLOMÉ; BELWARD, 2005). O mapa global do projeto possui originalmente mais de 40 classes, sendo que no mapa da América do Sul constam 24 classes. Já o projeto Global Forest Change (GFC) é uma parceria entre a Universidade de Maryland, Google, United States Geological Survey (USGS) e National Aeronautics and Space Administration (NASA), e surgiu com o propósito de identificar áreas onde a cobertura arbórea foi perdida em todo o mundo (HANSEN et al., 2013). Os dados foram produzidos utilizando mais de 600.000 imagens dos satélites Landsat. O Copernicus Global Land Services (CGLS) também é uma iniciativa da Comissão Europeia em parceria com outras instituições que, em 2019, lançou um mapa global utilizando 2015 como ano de referência e imagens do PROBA-V. A acurácia final do produto foi de $80 \%$ (BUCHHORN et al., 2020), considerada alta para um mapa dessa abrangência.

A Tabela 1 apresenta um resumo das principais iniciativas de mapeamento da vegetação da Caatinga, levando em consideração os seguintes aspectos: escala de abrangência (bioma, estadual), referência, período mapeado, tipo de dado de satélite utilizado (incluindo o sensor), técnica(s) empregada(s) para produzir o 
mapeamento e número de classes adotadas na legenda. É importante destacar que as iniciativas que abrangeram mais de um bioma nem sempre fizeram uso da mesma metodologia para todos os biomas, portanto, as informações da Tabela 1 aplicam-se exclusivamente à Caatinga.

Tabela 1 - Resumo das principais informações das iniciativas de mapeamento da vegetação que englobam a Caatinga.

\begin{tabular}{|c|c|c|c|c|c|}
\hline Abrangência & Projeto/Referência & Período & Dado Óptico & Técnica & Legenda \\
\hline Global & $\begin{array}{c}\text { GLC2000 } \\
\text { Eva et al. }(2002)\end{array}$ & 2000 & SPOT-4 & $\begin{array}{l}\text { Classificação } \\
\text { ISODATA }\end{array}$ & 24 classes \\
\hline Global & $\begin{array}{c}\text { GFC } \\
\text { Hansen et al. (2013) }\end{array}$ & $2000-2019$ & $\begin{array}{l}\text { Landsat (TM, } \\
\text { ETM+ e OLI) }\end{array}$ & $\begin{array}{l}\text { Algoritmo baseado } \\
\text { em árvore de } \\
\text { decisão }\end{array}$ & $\begin{array}{c}\text { \% de cobertura } \\
\text { florestal, ganho e } \\
\text { perda }\end{array}$ \\
\hline Global & $\begin{array}{c}\text { CGLS } \\
\text { Buchhorn et al. } \\
(2019)\end{array}$ & 2015 & PROBA-V & Random Forest & 23 classes \\
\hline Nacional & $\begin{array}{c}\text { ProVeg-NEB } \\
\text { Vieira et al. (2013) }\end{array}$ & 2000 e 2010 & $\begin{array}{l}\text { Landsat (TM e } \\
\text { ETM+) }\end{array}$ & $\begin{array}{l}\text { Classificação não- } \\
\text { supervisionada } \\
\text { ISOSEG }\end{array}$ & 7 classes \\
\hline $\begin{array}{c}\text { Nacional } \\
\text { (por bioma) }\end{array}$ & $\begin{array}{c}\text { MapBiomas/ } \\
\text { MapBiomas (2020) }\end{array}$ & $1985-2018$ & $\begin{array}{l}\text { Landsat (TM, } \\
\text { ETM+ e OLI) }\end{array}$ & Random Forest & 27 classes \\
\hline Bioma & $\begin{array}{c}\text { PROBIO } \\
\text { MMA (2006) }\end{array}$ & 2002 & Landsat (ETM+) & $\begin{array}{l}\text { Classificação } \\
\text { Supervisionada }\end{array}$ & 29 classes \\
\hline Bioma & $\begin{array}{c}\text { PMDBBS } \\
\text { MMA/IBAMA } \\
(2011)\end{array}$ & $2002-2011$ & $\begin{array}{l}\text { Landsat (TM) e } \\
\text { CBERS-2B }\end{array}$ & Interpretação Visual & 2 classes \\
\hline Bioma & $\begin{array}{c}\text { PMABB } \\
\text { Fundo Amazônia } \\
\qquad(2020)\end{array}$ & $2000-2020$ & $\begin{array}{l}\text { Landsat e } \\
\text { similares }\end{array}$ & Interpretação Visual & 2 classes \\
\hline Estado da Bahia & $\begin{array}{c}\text { INEMA } \\
\text { Consórcio } \\
\text { GeoBahia }(2018)\end{array}$ & $\begin{array}{l}\text { Único (mosaico de } \\
\text { 2012/2014) }\end{array}$ & RapidEye & $\begin{array}{c}\text { Classificação } \\
\text { orientada a objeto } \\
\text { e Interpretação } \\
\text { Visual }\end{array}$ & 15 classes \\
\hline $\begin{array}{l}\text { Estado de } \\
\text { Pernambuco }\end{array}$ & $\begin{array}{c}\text { EMBRAPA } \\
\text { Accioly et al. (2017) }\end{array}$ & $\begin{array}{l}\text { Único (mosaico de } \\
\text { 2013/2014/2015) }\end{array}$ & Landsat (OLI) & $\begin{array}{c}\text { Fusão e } \\
\text { Interpretação Visual }\end{array}$ & 12 classes \\
\hline
\end{tabular}

Fonte: Os autores (2020).

Os dados da Tabela 1 evidenciam a baixa quantidade de iniciativas a nível de bioma ou nacional existentes para a Caatinga. Até março de 2011 (data de lançamento do PMDBBS para a Caatinga), somente o mapeamento do PROBIO estava disponível para o bioma. O mapeamento do PROBIO representou um grande avanço para a Caatinga, que até então carecia de mapas de cobertura vegetal produzidos por dados ópticos de observação da Terra. Embora o PMDBBS tenha usado os dados do PROBIO como ponto de partida para desenvolver suas atividades, o foco exclusivo foi o monitoramento do desmatamento no bioma e, por isso, o projeto adotou uma legenda binária (área desmatada ou não).

Também é evidente na Tabela 1 que o Landsat foi o principal satélite utilizado para gerar mapeamentos na Caatinga. Esse padrão praticamente homogêneo na escolha do sistema sensor pode ser explicado pelo fato dos dados Landsat terem a maior cobertura contínua da superfície terrestre, em comparação com outros dados de Sensoriamento Remoto (LOVELAND; DWYER, 2012). Além do Landsat, o PMDBBS também usou as imagens do sensor High Resolution Camera (HRC) da série China-Brazil Earth-Resources Satellite (CBERS2B). A forma de aquisição das imagens também variou. O PROBIO e o PMDBBS adquiriram os dados pelo INPE, enquanto o MapBiomas utilizou o catálogo da plataforma Google Earth Engine (GORELICK et al., 2017) para construir mosaicos e processar dados. O ProVeg-NEB, por sua vez, adquiriu 162 imagens de uma empresa privada para compor o mosaico do Nordeste do Brasil (ano de referência 2000).

Outro aspecto que merece ser discutido é a técnica utilizada por cada iniciativa para gerar seu produto 
final. O PMDBBS adotou o procedimento de identificação de polígonos de áreas desmatadas, com uma determinação de área mínima mapeada de 2 hectares (MMA/IBAMA, 2011). As análises do projeto foram feitas por interpretação visual e digitalização manual das feições de desmatamento, identificadas nas áreas dos polígonos de remanescentes. Ainda nesse caminho, alguns estudos utilizaram diferentes recursos para favorecer o processo de percepção visual. Foi o caso do dado gerado por Accioly et al. (2017), que utilizaram a fusão de imagens por meio do software Geographic Resources Analysis Support System (GRASS). A fusão é uma técnica de realce utilizada em imagens multiespectrais que resulta em um dado com resolução espacial melhorada. O tipo de fusão utilizado pelos autores foi a Intensity-Hue-Saturation (IHS), onde a banda pancromática é combinada com as 3 bandas assinaladas em uma composição RGB, que no caso foram as bandas 6, 5 e 4 do Landsat-8/OLI, respectivamente.

O ProVeg-NEB utilizou a técnica de classificação não-supervisionada ISOSEG. Esse método examina inúmeros pixels desconhecidos e os divide em um determinado número de classes a partir de agrupamentos dos valores das imagens. Há também iniciativas que utilizaram técnicas de classificação supervisionada, como o PROBIO. Esse tipo de classificação requer a seleção de amostras prévias por um usuário, porém o relatório oficial do PROBIO não especifica o classificador que foi empregado. O MapBiomas também tem seguido uma lógica de processamento baseada em algoritmos de classificação supervisionada em cada coleção. Mais especificamente na Coleção 2, o projeto gerou suas classificações utilizando árvores de decisão cujos parâmetros foram definidos empiricamente. Isso quer dizer que todas as métricas utilizadas como nós das árvores tiveram seus valores testados a fim de averiguar aqueles que resultariam em uma representação mais fidedigna das classes nos mapeamentos gerados para cada ano.

No entanto, testar esses dados empiricamente para toda a série temporal demanda tempo e pode gerar maiores imprecisões. Com isso, a coleção 2.3 incorporou o Random Forest (BREIMAN, 2001) visando otimizar o tempo e aprimorar a qualidade dos mapeamentos. O Random Forest é uma técnica de classificação por aprendizado de máquina que também se baseia em árvores de decisão, ficando a cargo do analista apenas a seleção das amostras para representar a classe-alvo da maneira mais realista possível. Após a incorporação do Random Forest, o MapBiomas teve uma melhoria considerável na acurácia de seus mapeamentos, o que justificou o emprego do algoritmo nas coleções subsequentes.

No que diz respeito à legenda, é comum observar diferentes níveis de distribuição das classes nos mapeamentos da vegetação. Baseando-se nas iniciativas da Caatinga, um primeiro nível de legenda pode estar associado à natureza da área, ou seja, se há ou não presença de vegetação. Um segundo nível geralmente separa a cobertura vegetal nativa da vegetação antropizada, além de individualizar áreas urbanas, solo exposto e corpos d'água. Por fim, um terceiro nível cria um maior número de subclasses para as classes de primeiro nível, aumentando o detalhamento da legenda. Geralmente, quanto maior o nível de detalhamento da legenda, maior é a demanda por uma metodologia mais robusta de processamento e interpretação dos dados.

Dentre os mapeamentos que utilizaram legendas de primeiro nível está o PMDBBS, que adotou apenas as classes antrópica e natural para mapear o desmatamento, não havendo identificação do tipo de uso da terra. A classe antrópica está associada às áreas desmatadas, enquanto a classe natural, aos remanescentes de vegetação. O PROBIO utilizou alguns critérios para identificar remanescentes vegetais, tais como a existência de vestígios de antropismo e a estrutura da vegetação. Para mapear os remanescentes de vegetação natural, a legenda foi baseada na mesma definição do IBGE (2012). Dentre as formações vegetais características da Caatinga estão as classes: savana-estépica florestada, arborizada, parque ou gramíneo-lenhosa, e formação com influência fluvial e/ou lacustre arbórea, arbustiva ou herbácea. A legenda do MapBiomas é a mesma para todos os biomas, não incluindo classes específicas da Caatinga. As classes do projeto são: 1. Floresta (inclui formações florestais e savânicas, mangues, e floresta plantada); 2. Formação Natural não Florestal (inclui áreas úmidas não florestais, formações campestres, afloramentos e apicum); e 3. Agropecuária (inclui pastagens e agricultura). O ProVeg-NEB, por sua vez, utilizou sete classes no mapa de 2000, ampliando a legenda para 19 classes no mapa de 2010.

Em relação às estratégias de avaliação da acurácia, o PMDBBS adotou o índice de exatidão global. Em resumo, foi feita uma amostragem aleatória estratificada cujo número de amostras foi calculado por uma função binomial. Os pontos amostrais foram interpretados pela plataforma web desenvolvida por Adami et al. 
(2012) para avaliação da acurácia temática dentro do Virtual Laboratory of Remote Sensing Time-Series (FREITAS et al., 2011). Por fim, a exatidão global e os erros de comissão e omissão foram calculados após os pontos serem validados por um intérprete independente.

O MapBiomas comparou seus resultados com mapas de referência existentes e avaliou a acurácia usando métodos estatísticos e amostragem independente de pontos. Para a Caatinga, foram validados 9.738 pontos para cada ano baseado em interpretação visual de amostras de pixel do Landsat, inspecionadas por três intérpretes independentes. A validação ocorreu na plataforma web Temporal Visual Inspection (TVI), desenvolvida pelo Laboratório de Processamento de Imagens e Geoprocessamento da Universidade Federal de Goiás (LAPIG/UFG), a qual disponibiliza acesso a dados do MODIS, série temporal de dados de precipitação, além de imagens do Google Earth. O cálculo da acurácia foi baseado em matriz de erro e acurácia global, do produtor e do usuário, conforme definido por Stehman (2009), Stehman (2014) e Olofsson et al. (2014).

A maioria dos estudos atuais que expandem sua análise para décadas muito distantes não conta com dados de referência (campo ou imagens) para validar seus produtos. No caso da Caatinga, a ausência desses dados é ainda maior. Assim, Beuchle et al. (2015) avaliaram a qualidade dos mapas que produziram para o bioma com base em uma análise da consistência. Essa metodologia pressupõe que medições em um pequeno subconjunto desempenhada por um intérprete independente usando o mesmo método, deve produzir resultados semelhantes ou mais precisos. (MONGE; MARCO; CERVIGÓN, 2002).

\section{STATUS DA VEGETAÇÃO DA CAATINGA}

A Figura 4 traz um comparativo dos valores percentuais de vegetação mapeada pelo PROBIO, PMDBBS e MapBiomas, as três iniciativas que atualmente são mais utilizadas como referência para discutir dados ou validar produtos de outros estudos. Para o PROBIO, 2002 consta na figura por ser o único ano de referência que o projeto mapeou. No caso do PMDBBS, foram incluídos os valores do primeiro e último ano de dados gerados pelo projeto (2002 e 2011). Já para o MapBiomas, além do primeiro e último ano mapeados até a data de redação deste artigo (1985 e 2018), foram incluídos também os anos de 2002 e 2011 para fins de comparação com o PROBIO e PMDBBS. É importante esclarecer que os percentuais informados consideram tanto a vegetação natural como a plantada.

Figura 4 - Percentuais de vegetação remanescente da Caatinga produzidos pelas três principais iniciativas institucionais que mapearam a vegetação do bioma.

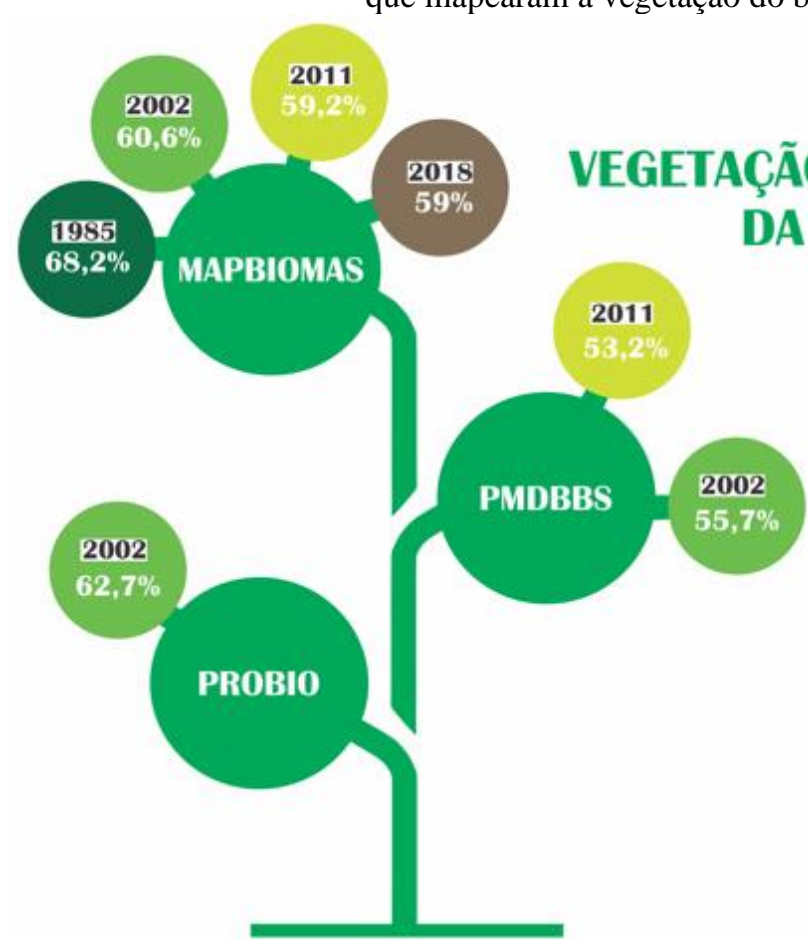

MAPBIOMAS - Projeto de Mapeamento Anual da Cobertura e Uso do Solo do Brasil

PMDBBS - Programa de Monitoramentodo Desmatamento nos Biomas Brasileiros por Satélite

PRoBIo - Projeto de Conservação e Utilização Sustentável da Diversidade Biológica Brasileira

Fonte: Os autores (2020). 
Para 2002, o percentual de vegetação remanescente do PMDBBS é 4,9\% e 7\% menor que os valores do MapBiomas e PROBIO, respectivamente. Um padrão similar é observado para 2011, com uma diferença de $6 \%$ entre os valores do PMDBBS e MapBiomas. Comparando os percentuais das três iniciativas em 2002, nota-se uma convergência maior entre os dados do PROBIO e do MapBiomas, com uma diferença de 2,1\%. Os dados do PROBIO indicam uma área de cobertura vegetal de $518.635 \mathrm{~km}^{2}$, do qual apenas a porção de Caatinga do norte do estado de Minas Gerais não foi incluída (MMA, 2006). Desse total, a vegetação nativa florestal equivale a $24,39 \%$, e a não-florestal, a 38,38\%. Além disso, as quatro subclasses de savana-estépica correspondem a 35,9\% da vegetação remanescente para o ano de 2002. Já os dados do PMDBBS para o mesmo ano representam uma área de cobertura vegetal da Caatinga equivalente a $460.327,6 \mathrm{~km}^{2}$.

A classe florestal do MapBiomas correspondeu a 56,1\% em 2002, enquanto a formação natural nãoflorestal, a 4,5\%. A primeira classe inclui as categorias de savana-estépica florestada, arbóreo-arbustiva, e parque, enquanto a savana-estépica gramíneo-lenhosa é englobada pela classe formação natural não-florestal. A Figura 5 apresenta os dados do MapBiomas de 1985 até 2018 para as duas classes de vegetação do primeiro nível da legenda do projeto, incluindo os dados de agropecuária. Conforme o gráfico exibe, a série temporal de 33 anos mostra uma perda de aproximadamente $79 \mathrm{mil} \mathrm{km}^{2}$ de cobertura vegetal (natural ou não) e um aumento diretamente proporcional da classe de agropecuária, com mudanças mais expressivas sendo observadas no fim da década de 80 e início da década de 90.

Figura 5 - Evolução temporal dos dados do MapBiomas para as classes de vegetação e agropecuária da Caatinga $60 \mathrm{M}$
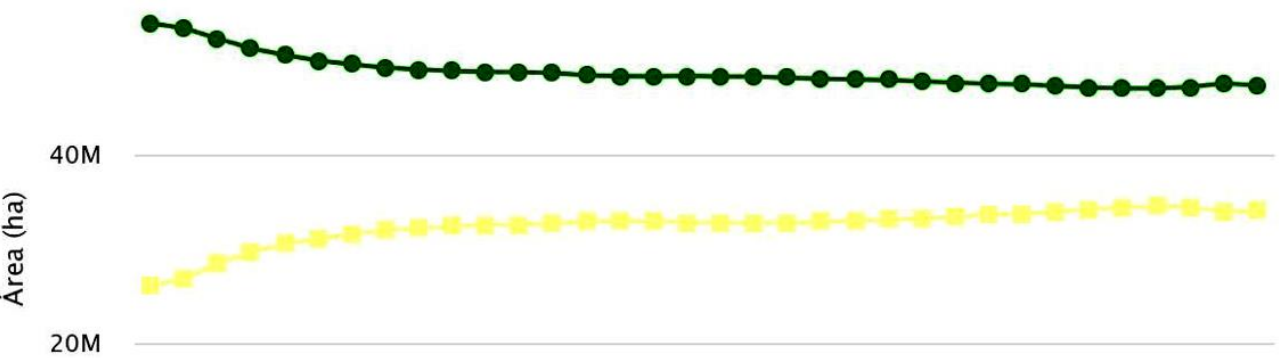

$20 \mathrm{M}$

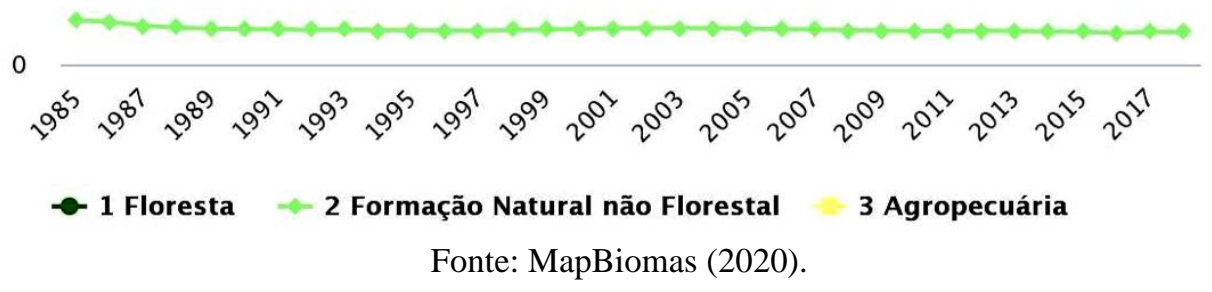

\section{OPORTUNIDADES E DESAFIOS PARA O MAPEAMENTO DA VEGETAÇÃO DA CAATINGA}

A conservação dos recursos naturais do bioma Caatinga é uma questão emergencial, especialmente levando-se em consideração a influência que a degradação e a perda de habitats naturais têm na intensificação das secas e no agravamento das mudanças climáticas. Existe também uma relação intrínseca entre eventos de seca e segurança alimentar no bioma. As secas severas e recorrentes da Caatinga ameaçam o desenvolvimento de cultivos agrícolas e, como consequência, criam sérios problemas sociais (MARENGO, 2009). Além disso, a ocorrência de secas representa um dos desastres ambientais mais dispendiosos. De acordo com Cunha et al. (2015), o evento de seca ocorrido em 2012/2013 resultou em perdas da magnitude de U\$ 1.6 bilhões na agricultura. É por esse e outros motivos que a quantificação da seca é imprescindível para minimizar impactos econômicos e socioambientais.

Diante desse contexto, os dados ópticos de observação da Terra tornam-se uma ferramenta de grande valia no alcance desse objetivo. De acordo com Wan et al. (2004), os dados do MODIS exercem um importante papel para o monitoramento da seca devido à alta resolução temporal e facilidade no acesso aos dados. 
Aproveitando as vantagens do MODIS, Tomasella et al. (2018) desenvolveram uma metodologia de mapeamento para monitorar o solo exposto, um dos indicadores de degradação da terra, a partir do estudo do comportamento do NDVI em um período de 17 anos. Já Vieira et al. (2015) identificaram diferentes níveis de susceptibilidade à desertificação no NEB com base na influência de 11 fatores (geologia, mudança de uso e cobertura da terra, densidade populacional, etc.), os quais foram simulados para os anos 2000 e 2010 . Esse estudo, que faz parte do projeto Sistema de Alerta Precoce de Secas e Desertificação (SAP) desenvolvido no INPE, indicou que 94\% do NEB varia de moderada a alta susceptibilidade à desertificação. Esse estudo também constatou que o número de áreas susceptíveis à desertificação aumentou em 4,6\% $\left(83,4 \mathrm{~km}^{2}\right)$, e que a maior parte dessas áreas estão na Caatinga.

Em relação às iniciativas institucionais e seu papel na mitigação dos efeitos das secas, projetos como o MapBiomas auxiliam no combate à desertificação na Caatinga através do monitoramento contínuo das mudanças de uso e cobertura da terra, o que viabiliza a fiscalização e previne desastres ambientais mais danosos. Uma alternativa do projeto nesse sentido foi a criação de um sistema de monitoramento de áreas degradadas e áreas de intervenções no NEB, o MapBiomas Áridas (2020). Essa iniciativa do MMA, financiada pelo Global Environmental Facility (GEF) e Programa das Nações Unidas para o Desenvolvimento (PNUD), visa gerar diagnósticos para a definição de metas governamentais que corroborem com a estratégia de neutralidade de degradação da terra.

Sobre o monitoramento dos remanescentes vegetais, a ausência de legislação reguladora, instrumentos econômicos, políticas públicas e oportunidades para a conservação da biodiversidade da Caatinga já haviam sido descritos por Leal et al. (2005) como obstáculos para implementar estratégias de conservação há 15 anos. Além disso, o papel da vegetação como indicador do estado de conservação da biota é importante para definir a presença ou ausência de habitats para as espécies, a manutenção de serviços ambientais ou mesmo o fornecimento de recursos essenciais para garantir a sobrevivência da população. Leal et al. (2003) também alertaram sobre a dificuldade de encontrar remanescentes de vegetação nativa maiores que $100 \mathrm{~km}^{2}$ na Caatinga. Complementarmente, dos 62,7\% da vegetação mapeada pelo PROBIO para 2002, 40,5\% corresponde aos remanescentes mais conservados. No entanto, a criação e implementação de Unidades de Conservação (UCs) na Caatinga ainda é um desafio atual. O mapa da Figura 6 exibe os percentuais de remanescentes vegetais mapeados pelo MapBiomas, bem como as UCs federais da Caatinga considerando os limites do IBGE (2019). 


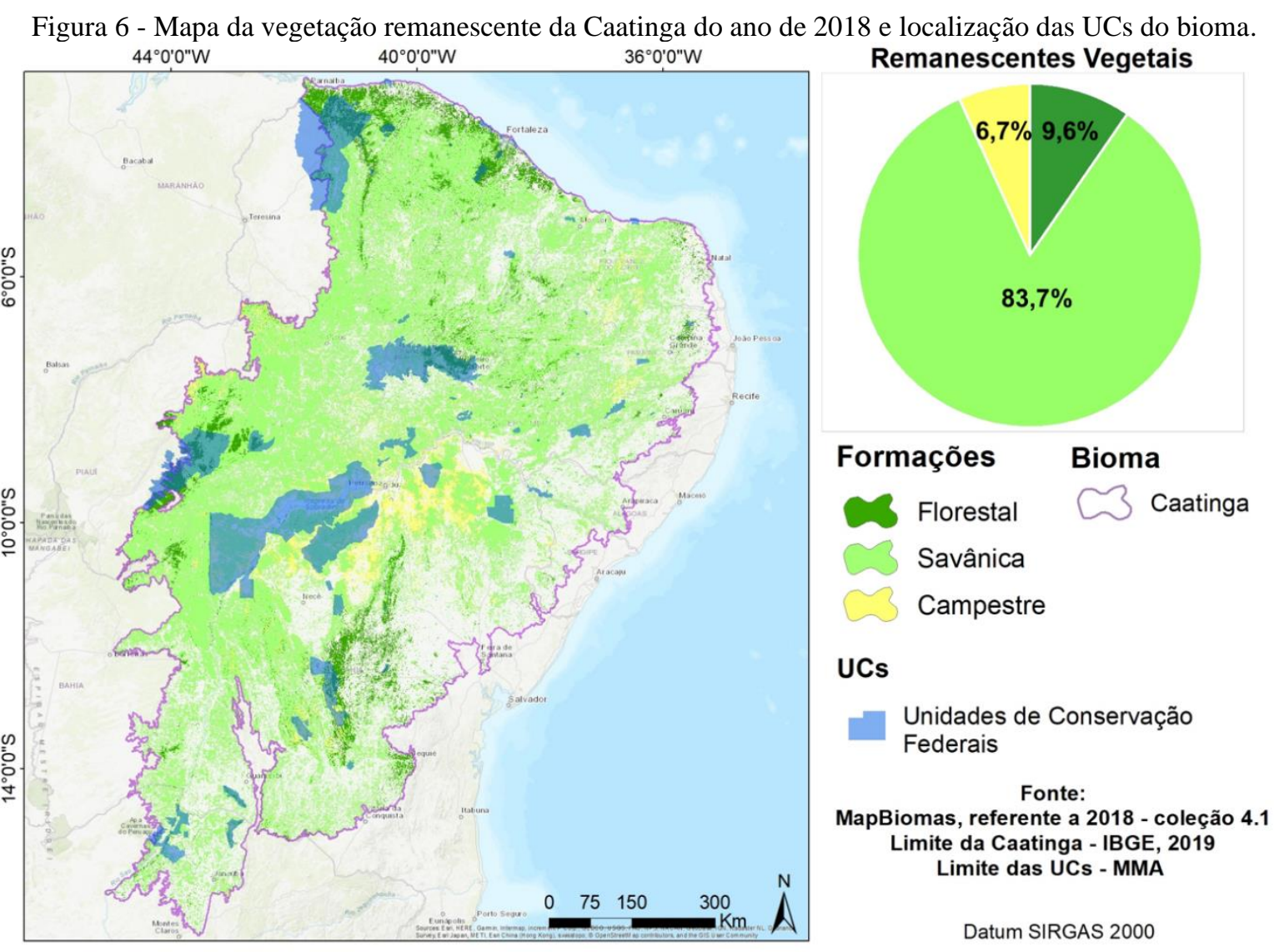

Fonte: Os autores (2020).

O bioma possui cerca de 5\% de sua área ocupada por 27 UCs federais (ICMBio, 2019), sendo que a maior parte está localizada no Ceará e Bahia, respectivamente. Do restante, Pernambuco, Piauí e Rio Grande do Norte possuem, cada um, três UCs federais em suas porções de Caatinga, ao passo que a Paraíba não apresenta nenhuma. Dos 5\%, pouco mais de $1 \%$ corresponde a UCs de proteção integral, havendo ainda somente 12 Reservas Particulares do Patrimônio Natural (RPPN) de âmbito federal no bioma. O mapa ainda revela que há poucas UCs criadas em formações florestais e campestres da Caatinga, que representam, respectivamente, 9,6\% e 6,7\% da vegetação remanescente, de acordo com os dados do MapBiomas de 2018.

A criação de UCs é uma alternativa para conter a fragmentação de habitats. Leal et al. (2005) apontaram aspectos que também já contribuíam para a implementação de uma agenda de conservação em larga escala na Caatinga, como a densidade populacional em várias partes do bioma e a modificação de habitats remanescentes, aliados ao longo histórico de pobreza e seca. Iniciativas de reflorestamento são raras na Caatinga e recuperar sua vegetação nativa ainda é um grande desafio, principalmente porque a cobertura vegetal pode levar várias décadas para se reestabelecer naturalmente (PEREIRA et al., 2003).

Para avaliar processos de desmatamento, regeneração ou reflorestamento em zonas semiáridas, os dados ópticos de observação da Terra são limitados pela alta variabilidade espaço-temporal da vegetação. De acordo com Mayes, Mustard e Melillo (2015), essa limitação é decorrente da ecologia regional complexa da vegetação aliada a fatores como práticas de uso da terra e regimes de perturbação. Tomasella et al. (2018) acrescentaram, ainda, que a ampla variedade de árvores, arbustos e pastagem distribuídos irregularmente no bioma, somados ao seu elevado grau de fragmentação, diversificam as respostas espectrais nessas paisagens.

Do ponto de vista espectral, as bandas que compreendem o intervalo do vermelho e infravermelho próximo são sensíveis ao vigor da vegetação verde (CURRAN, 1989). Por isso, a maior parte dos índices de vegetação foram desenvolvidos com base na reflectância do vermelho e infravermelho próximo - EVI, NDVI, entre outros. Porém, índices de vegetação desenvolvidos para dados multiespectrais são dificilmente relacionáveis com a fração não fotossintética da vegetação e a tarefa é ainda mais desafiadora quando há tentativa de diferenciá-la de solo exposto.

$\mathrm{Na}$ literatura, alguns estudos buscaram alternativas para preencher essa lacuna. Nagler, Daughtry e 
Goward (2000) criaram o Cellulose Absorption Index (CAI) e obtiveram êxito ao diferenciarem solos da fração não-fotossintética da vegetação. Asner e Heidebrecht (2002) também mostraram que o intervalo do infravermelho de ondas curtas (SWIR) foi bastante eficaz para essa finalidade. Entretanto, esses estudos foram conduzidos em imagens de alta resolução espectral, as quais são inviáveis para aplicações em larga escala devido ao seu alto custo de aquisição e indisponibilidade em determinadas áreas.

O comportamento fenológico dos ambientes semiáridos também merece destaque nessa discussão. Nesse sentido, estudos recentes exploraram novas alternativas em imagens Landsat. Silveira et al. (2019) desenvolveram um método de detecção de mudança baseada em objeto para atenuar os efeitos da fenologia nos desmatamentos e queimadas de florestas tropicais sazonalmente secas. Já Miranda et al. (2020) desenvolveram e avaliaram modelos baseados nos índices Plant Area Index (PAI) e Leaf Area Index (LAI) a partir de medições em campo. De acordo com Albuquerque, Lima e Araújo (2012), dados fenológicos precisam ser coletados para os diversos tipos de vegetação da Caatinga dado o elevado grau de distúrbio antropogênico, redução da disponibilidade hídrica e maior sensibilidade do bioma às mudanças climáticas. Por isso, avaliar métodos para reescalonar dados fenológicos promoverá avanços sobre a real influência da fenologia nas respostas das florestas tropicais sazonalmente secas às variáveis ambientais.

Uma abordagem muito promissora desenvolvida na última década para estudos fenológicos é o Sensoriamento Remoto da superfície próxima, que se baseia na repetição de fotografias digitais em alta frequência - são as chamadas Phenocams (RICHARDSON et al., 2009; SONNENTAG et al., 2012). Esse método consiste na instalação de câmeras digitais próximas à superfície terrestre com o objetivo de monitorar mudanças na vegetação na escala ecossistêmica (ALBERTON et al., 2019). Alberton et al. (2017) forneceram maiores detalhes dessa abordagem e destacaram algumas vantagens dessa metodologia - os dados podem ser registrados por dia ou por hora, havendo uma redução considerável no tempo gasto em trabalhos de campo. No Brasil, o primeiro e único estudo desenvolvido na Caatinga foi conduzido por Alberton et al. (2019), onde os autores compararam as variações fenológicas com o Cerrado e observaram que, na Caatinga, os efeitos da chuva são maiores na vegetação, reforçando o que já foi apontado na seção 2.2.

Especialmente na última década, sensores foram colocados em órbita e abriram oportunidades para novos estudos. Eles possuem não só características únicas, mas apresentam vantagens e desvantagens associadas. Por exemplo, o PROBA-V, lançado em 2013 como uma continuação do SPOT, tem seus dados produzidos a cada dois dias com uma resolução espacial de 300 metros e a cada 5 dias no nadir com uma resolução de 100 metros (STERCKX et al., 2014). Suas imagens estão disponibilizadas em reflectância de superfície e têm sido utilizadas para mapear áreas a nível nacional e global. Em melhor resolução espacial (10 e 20 metros), as imagens do sensor MultiSpectral Instrument (MSI) dos satélites Sentinel-2A e Sentinel 2B fornecem, em conjunto, imagens no intervalo temporal de aproximadamente 4 dias (DRUSCH et al., 2012).

No âmbito do processamento de imagens, o Google Earth Engine (GEE) merece destaque pela sua capacidade de processar dados em nuvem, tendo sido uma das grandes vantagens da metodologia do MapBiomas. O advento do GEE reduziu significativamente o tempo de processamento e otimizou as rotinas de preparo e análise das imagens. Atualmente, a plataforma tem sido utilizada para estudos em diferentes campos do conhecimento. Dentre as aplicações recentes que podem ser replicadas na Caatinga, destacam-se monitoramento da fenologia (QI et al., 2020), indicadores sazonais para eventos extremos de seca (LAI et al., 2020) e detecção de mudanças da cobertura da terra (SIDHU; PEBESMA; CÂMARA, 2018).

Para coletar dados para a validação de mapeamentos, a plataforma Geo-Wiki possui um elevado potencial. O projeto Copernicus Global Land Cover Services (C-GLOPS) tem obtido bastante êxito no uso dessa plataforma para calcular a acurácia de seus mapeamentos globais. Além da interface gráfica, o Geo-Wiki disponibiliza imagens de alta resolução que podem ser combinados com informações de índices espectrais calculados em imagens do Sentinel-2 e PROVA-V para auxiliar os intérpretes na tomada de decisões. Um outro aspecto positivo da plataforma é a conectividade com o Google Earth.

Por fim, um projeto nacional inovador que permitirá que cientistas e usuários produzam informações sobre mudanças de cobertura da terra nos biomas brasileiros é o Brazil Data Cube, uma plataforma para análise e visualização de grandes volumes de dados geoespaciais que está em desenvolvimento desde janeiro de 2019 pelo INPE (2019). O objetivo central desse projeto é criar cubos de dados multidimensionais prontos para 
análise usando aprendizado de máquina e análise de séries temporais de satélites de observação da Terra de média resolução espacial, como Landsat (período de 1974 a 1984) e CBERS. Esses dados serão de extrema importância para a Caatinga porque produzirão informações que antecedem 1985, período mais antigo mapeado até então (pelo MapBiomas) usando dados ópticos de observação da Terra.

No que tange o desenvolvimento de pesquisas futuras em prol do mapeamento da vegetação do bioma e suas implicações diretas para a economia e sociedade, algumas respostas devem ser oferecidas para perguntas relevantes. No âmbito dos dados ópticos, alguns desafios futuros para o mapeamento da vegetação da Caatinga incluem o desenvolvimento e avaliação de novos métodos para detecção, classificação e filtragem de nuvens e suas respectivas sombras. Portanto, como investigar quais incertezas do mapeamento da vegetação do bioma estão associadas à presença de nuvens cúmulos e suas respectivas sombras? A presença de nuvens cúmulos é muito comum ao longo de toda faixa litorânea norte da Caatinga. Com isso, a localização regional e morfológica das nuvens e sombras podem não permitir ou adicionar erros ao mapeamento da vegetação, principalmente quando o objetivo é estudar sua variabilidade intra-anual e espacial em termos de fenologia (DUTRA et al., 2020).

Sob a perspectiva da fenologia, qual estratégia deve ser adotada para a manutenção e expansão das redes de observação de campo para melhor representar a heterogeneidade espaço-temporal da vegetação da Caatinga? Como esses dados podem auxiliar no desenvolvimento de algoritmos e metodologias ajustados especificamente para regiões semiáridas, ou ainda, na avaliação de novos produtos e sensores? Como os dados ópticos de Sensoriamento Remoto podem auxiliar os tomadores de decisão na tentativa de mitigar os impactos da seca na vegetação de ambientes semiáridos e, consequentemente, na população que depende direta ou indiretamente desses ecossistemas? Uma alternativa seria o desenvolvimento de sensores capazes de detectar e monitorar a variação diurna no uso da água, estresse de umidade e fotossíntese nesses ecossistemas, o que não é detectável pelos sensores de baixa resolução temporal disponíveis atualmente.

No que diz respeito aos modelos numéricos de tempo e clima, é necessário parametrizar os processos relacionados à superfície terrestre que estão fortemente correlacionados com o tipo da vegetação, uso e cobertura do solo. Dentre esses parâmetros, destacam-se albedo de superfície, evapotranspiração e rugosidade aerodinâmica da superfície. Nesse contexto, o mapeamento detalhado inter e intra-anual da vegetação da Caatinga pode trazer novas perspectivas e oportunidades para as pesquisas que visam compreender os impactos das mudanças climáticas em ecossistemas semiáridos e o grau de resiliência da vegetação local. Além disso, pesquisas em tempo e clima também podem ser relacionadas às estimativas e incertezas dos recursos eólicos e solar. Portanto, como relacionar os vários aspectos da vegetação com energias renováveis e simulações de tempo e clima?

O NEB é reconhecido como a região com o maior potencial para geração de energias renováveis do Brasil, principalmente da fonte solar e eólica. Nesse contexto, o mapeamento detalhado da vegetação é fundamental tanto para definir novas Unidades de Conservação, avaliar impactos ambientais de projetos existentes ou planejados, como também para a própria avaliação dos recursos eólicos e solar nas áreas de interesse de instalação de novos projetos.

Outra pergunta desafiadora é: como desenvolver metodologias que permitam considerar os aspectos geomorfológicos locais para a caracterização e quantificação desse tipo de vegetação e sua fragmentação em todo o bioma? Em escala local de mapeamento, os aspectos geomorfológicos e topográficos, especialmente nas regiões de terreno complexo como serras, escarpas e bordas das chapadas, podem dificultar o mapeamento e identificação da vegetação devido às sombras do relevo e às características fenológicas da vegetação.

Por fim, como produzir dados que atendam as demandas dos formuladores de políticas públicas para uma gestão sustentável da Caatinga nas diferentes esferas de governo? Certamente esse é um dos maiores desafios, visto que requer incentivo em desenvolvimento tecnológico, computacional, analítico, além da ampliação da participação dos gestores nas etapas de planejamento e produção desses dados.

\section{CONCLUSÃO}

O mapeamento da vegetação da Caatinga a partir de dados ópticos de observação da Terra se iniciou em um processo bastante tardio e retardatário. Considerando que mais de $70 \%$ das iniciativas que mapearam 
o bioma até o presente utilizaram um ou mais sensores da série Landsat, e que o primeiro satélite da série foi colocado em órbita na década de 70, é inegável o fato de o bioma ter sido negligenciado por décadas. O lançamento dos primeiros dados efetivos sobre a vegetação da Caatinga em 2002 (PROBIO) comprova isso, visto que ocorreu três décadas após o lançamento do primeiro satélite Landsat.

Dentre todas as iniciativas apresentadas, o MapBiomas se destaca por se beneficiar de todos os atributos do sistema Landsat, incluindo os mais de 30 anos de dados disponíveis. Além disso, trata-se da única iniciativa contínua que abrange todo o território brasileiro, sendo também a única a produzir o maior conjunto de dados de uso e cobertura da terra para a Caatinga. Isso representa um grande avanço para o conhecimento, pois estimula o surgimento de novas iniciativas e fornece subsídios mais consistentes para o planejamento e execução de políticas públicas.

Uma estratégia para aprimorar a difusão do conhecimento sobre a vegetação da Caatinga, por exemplo, é investir em iniciativas de mapeamento a nível estadual. Dos estados inseridos nos limites do bioma, somente Bahia e Pernambuco possuem mapeamentos de referência. Portanto, multiplicar os incentivos à produção de mapas de referência em outros estados tende a não somente tornar a gestão territorial mais eficaz a nível local, como também fortalecer mapeamentos em escala de bioma ou nacionais, uma vez que haverá novas alternativas para comparar e validar esses produtos.

A parceria com universidades e institutos de pesquisa da região Nordeste e a expansão da rede de compartilhamento de dados entre as instituições também se mostra uma solução de benefício mútuo, especialmente porque são essas instituições que lideram o número de estudos sobre a Caatinga, conforme salientado pela estatística do WoS. Esse fato reforça, por si só, a importância de se criar oportunidades para financiar grupos de pesquisa e programas de graduação e pós-graduação locais, especialmente por se tratar de uma região historicamente menos privilegiada.

Apesar dos estudos e iniciativas identificados neste trabalho, é necessário alertar que muito ainda precisa ser investigado sobre a vegetação da Caatinga no âmbito dos dados ópticos de observação da Terra. Mapear as mudanças de uso e cobertura da terra no bioma é primordial para desenvolver novas metodologias para estimar estoques de carbono e calcular o grau de fragmentação da paisagem. Ainda, esses mapeamentos permitem criar novas métricas para avaliar o impacto das dinâmicas de alteração da cobertura da terra nas mudanças climáticas, no processo de desertificação e até mesmo na saúde humana. Portanto, combinar técnicas robustas de mapeamento com estratégias de validação que aumentem a acurácia desses produtos pode não só garantir a segurança alimentar da população, mas subsidiar políticas públicas em prol de uma gestão mais sustentável da Caatinga.

\section{Agradecimentos}

Os autores agradecem ao Conselho Nacional de Desenvolvimento Científico e Tecnológico (CNPq) pelo apoio financeiro ao presente estudo (CNPq Universal - 431172/2018-8) e pelas bolsas concedidas (Khalil: CNPq/PCI-INPE - 444327/2018-5; Andeise: CNPq - 380716/2019-4; Marceli: CNPq - 140378/2018-9; Yosio: CNPq - Bolsa de Produtividade 303299/2018-5). Agradecimentos especiais: ao Instituto Nacional de Pesquisas Espaciais, pela infraestrutura concedida para o desenvolvimento da pesquisa; a Carolinna Maia pelo suporte no desenvolvimento da Figura 4; a Frans Pareyn e Washington Franca Rocha, pelos materiais e informações cedidas; a Rodrigo Vasconcelos pelas fotos usadas na Figura 2; e aos revisores anônimos pelas contribuições para a melhoria do artigo.

\section{Contribuição dos Autores}

A pesquisa foi conceituada por Khalil Ganem/Andeise Dutra e desenhada por Khalil Ganem. As figuras 1 e 6 foram elaboradas por Marceli Terra. A redação do texto foi feita por Khalil Ganem e contou com a colaboração de Andeise Dutra, Marceli Terra, Ramon Freitas, Rosana Grecchi e Rita Vieira. A revisão e edição do manuscrito foi feita por Egidio Arai, Fabrício Brito, Claudia Sampaio, Valdete Duarte e Yosio Shimabukuro. 


\section{Conflitos de Interesse}

Os autores declaram não haver conflitos de interesse.

\section{Referências}

ACCIOLY, L. C. O.; SILVA, E. A.; CAVALCANTI JUNIOR, E. A. C.; ALVES, E. S.; PEREIRA, A. G. S.; SILVA, R. S.; RAMOS, R. R. D.; SILVA, R. R. Mapeamento do Uso e Cobertura das Terras do Semiárido Pernambucano (escala 1:100.000). Rio de Janeiro: Embrapa Solos, 2017.

ADAMI, M.; MELlO, M. P.; AGUIAR, D. A.; RUDORFF, B. F. T.; SOUZA, A. F. A Web Platform Development to Perform Thematic Accuracy Assessment of Sugarcane Mapping in South-Central Brazil. Remote Sensing, v. 4, n. 10, p. 3201-3214, 2012. DOI. 10.3390/rs4103201

ALBERTON, B.; TORRES, R. S.; CANCIAN, L. F.; BORGES, B. D.; ALMEIDA, J.; MARIANO, G. C.; SANTOS, J.; MORELLATO, L. P. C. Introducing digital cameras to monitor plant phenology in the tropics: applications for conservation. Perspectives in Ecology and Conservation, v. 15, n. 2, p. 82-90, 2017. DOI. 10.1016/j.pecon.2017.06.004

ALBERTON, B.; TORRES, R. S.; SILVA, T. S. F.; ROCHA, H. R.; MOURA, M. S. B.; MORELLATO, L. P. C. Leafing Patterns and Drivers across Seasonally Dry Tropical Communities. Remote Sensing, v. 11, n. 19, 2019. DOI. 10.3390/rs11192267

ALBUQUERQUE, S.; BANDEIRA, G. Effect of thinning and slashing on forage phytomass from a caatinga of Petrolina, Pernambuco, Brazil. Pesquisa Agropecuária Brasileira, v. 30, n. 6, p. 885-891, Jun. 1995.

ALBUQUERQUE, S. G. Caatinga vegetation dynamics under various grazing intensities by steers in the semiarid Northeast, Brazil. Journal of Range Management, v. 52, n. 3, p. 241-248, 1999.

ALBUQUeRQUe, U. P.; ARAÚJO, E. L; EL-DEIR, A. C. A.; LIMA, A. L. A.; SOUTO, A.; BEZERRA, B. M.; FERRAZ, E. M. N.; FREIRE, E. M. X., et al. Caatinga revisited: Ecology and conservation of an important seasonal dry forest. The Scientific World Journal, v. 2012, 2012. DOI. 10.1100/2012/205182

ALVARES, C. A.; STAPE, J. L.; SENTELHAS, P. C.; GONÇALVES, J. L. M.; SPAROVEK, G. Köppen's climate classification map for Brazil. Meteorologische Zeitschrift, v. 22, n. 6, p. 711-728, 2013. DOI. 10.1127/0941-2948/2013/0507

ALVES, J. J. A.; ARAÚJO, M. A.; NASCIMENTO, S. S. Degradação da Caatinga: uma investigação ecogeográfica. Revista Caatinga, v. 22, n. 3, p. 126-135, 2009.

ANDRADE-LIMA, D. The caatinga dominium. Revista Brasileira de Botânica, v. 4, p. 149-153, 1981.

ASNER, G. P.; HEIDEBRECHT, K. B. Spectral unmixing of vegetation, soil and dry carbon cover in arid regions: Comparing multispectral and hyperspectral observations. International Journal of Remote Sensing, v. 23, n. 19, p. 3939-3958, 2002. DOI. 10.1080/01431160110115960

BARBOSA, H. A.; HUETE, A. R.; BAETHGEN, W. E. A 20-year study of NDVI variability over the Northeast Region of Brazil. Journal of Arid Environments, v. 67, n. 2, p. 288-307, 2006. DOI. 10.1016/j.jaridenv.2006.02.022

BARBOSA, H. A.; LAKSHMI KUMAR, T. V. Influence of rainfall variability on the vegetation dynamics over Northeastern Brazil. Journal of Arid Environments, v. 124, p. 377-387, 2016. DOI. 10.1016/j.jaridenv.2015.08.015

BARBOSA, H. A.; LAKSHMI KUMAR, T. V.; PAREDES, F.; ELLIOTT, S.; AYUGA, J. G. Assessment of Caatinga response to drought using Meteosat-SEVIRI Normalized Difference Vegetation Index (20082016). ISPRS Journal of Photogrammetry and Remote Sensing, v. 148, n. January, p. 235-252, 2019. DOI. 10.1016/j.isprsjprs.2018.12.014

BARTHOLOMÉ, E.; BELWARD, A. S. GLC2000: A new approach to global land cover mapping from earth observation data. International Journal of Remote Sensing, v. 26, n. 9, p. 1959-1977, 2005. DOI. $10.1080 / 01431160412331291297$ 
BEUCHLE, R.; GRECCHI, R. C.; SHIMABUKURO, Y. E.; SELIGER, R.; EVA H. D.; SANO, E.; ACHARD, F. Land cover changes in the Brazilian Cerrado and Caatinga biomes from 1990 to 2010 based on a systematic remote sensing sampling approach. Applied Geography, v. 58, p. 116-127, 2015. DOI. 10.1016/j.apgeog.2015.01.017

BRASIL. Resolução n ${ }^{\circ}$ 115, de 23 de novembro de 2017. Aprova a Proposição no 113/2017, que acrescenta municípios a relação aprovada pela Resolução CONDEL no 107, e 27 de julho de 2017. SUDENE, v. n. 115, n. 23 de nov. de 2017, 2017a.

BRASIL. Resolução ${ }^{\circ}$ 107, de 27 de julho de 2017. Estabelece critérios técnicos e científicos para delimitação do Semiárido Brasileiro e procedimentos para revisão de sua abrangência. SUDENE, v. n. 107, n. 27 de jul. de 2017, $2017 b$.

BREIMAN, L. Random Forests. Machine Learning, v. 45, n. 1, p. 5-32, 2001. DOI. 10.1023/A:1010933404324

BRITO, A. F.; PRESLEY, S. J.; SANTOS, G. M. M. Temporal and trophic niche overlap in a guild of flowervisiting ants in a seasonal semi-arid tropical environment. Journal of Arid Environments, v. 87, p. 161167, 2012. DOI. 10.1016/j.jaridenv.2012.07.001

BUCHHORN, M.; LESIV, M.; TSENDBAZAR, N. E.; HEROLD, M.; BERTELS, L.; SMETS, B. Copernicus global land cover layers-collection 2. Remote Sensing, v. 12, n. 6, p. 1-14, 2020. DOI. $10.3390 / \mathrm{rs} 12061044$

BUCHHORN, M.; SMETS, B.; BERTELS, L.; LESIV, M.; TSENDBAZAR, N. E.; LI, L. Copernicus Global Land Service: Land Cover 100m: version 2 Globe 2015: Product User Manual, nov. 2019. DOI. 10.5281/zenodo. 3606408

CAVALCANTI, L. C. S. Cartografia de paisagens: fundamentos. $2^{\mathrm{a}}$ ed. São Paulo: Oficina de Textos, 2018.

CHAVES, I. B.; LOPES, V. L.; FFOLLIOTT, P. F.; SILVA, A. P. P. Uma Classificação Morfo-Estrutural Para Descrição e Avaliação da Biomassa da Vegetação da Caatinga. Revista Caatinga, v. 21, n. 2, p. 204 213, 2008.

CONSÓRCIO GEOBAHIA. Mapeamento da Cobertura Vegetal do Estado da Bahia - Biomas Cerrado, Caatinga e Mata Atlântica. 2018.

CUNHA, A. P. M.; ALVALÁ, R. C.; NOBRE, C. A.; CARVALHO, M. A. Monitoring vegetative drought dynamics in the Brazilian semiarid region. Agricultural and Forest Meteorology, v. 214-215, p. 494505, 2015. DOI. 10.1016/j.agrformet.2015.09.010

CUNHA, J.; NÓBREGA, R. L. B.; RUFINO, I.; ERASMI, S.; GALVÃO, C.; VALENTE, F. Surface albedo as a proxy for land-cover clearing in seasonally dry forests: Evidence from the Brazilian Caatinga. Remote Sensing of Environment, v. 238, p. 111250, 2020. DOI. 10.0.3.248/j.rse.2019.111250

CURRAN, P. J. Remote sensing of foliar chemistry. Remote Sensing of Environment, v. 30, n. 3, p. 271278, 1989. DOI. 10.1016/0034-4257(89)90069-2

DRUSCH, M.; DEL BELLO, U.; CARLIER, S.; COLIN, O.; FERNANDEZ, V.; GASCON, F.; HOERSCH, B.; ISOLA, C.; LABERINTI, P.; MARTIMORT, P.; MEYGRET, A.; SPOTO, F.; SY, O.; MARCHESE, F.; BARGELLINI, P. Sentinel-2: ESA's Optical High-Resolution Mission for GMES Operational Services. Remote Sensing of Environment, v. 120, p. 25-36, 2012. DOI. 10.1016/j.rse.2011.11.026

DUTRA, A. C. Mapeamento e Monitoramento da Cobertura Vegetal do Estado da Bahia Utilizando Dados Multitemporais. 119p. Dissertação (Mestrado em Sensoriamento Remoto) - Instituto Nacional de Pesquisas Espaciais, São José dos Campos, 2019.

DUTRA, A. C.; ARAI, E.; SAMPAIO, C. B. V.; SHIMABUKURO, Y. E. Assessment of Spatial and Temporal Distribution of Clouds in Northeast Brazil (2000 -2019) using MODIS Data. Revista Brasileira de Cartografia, v. 72, n. 4, p. 681-696, 2020. DOI. 10.14393/rbcv72n4-53187

VAN ECK, N. J.; WALTMAN, L. Software survey: VOSviewer, a computer program for bibliometric mapping. Scientometrics, v. 84, n. 2, p. 523-538, 2010. DOI. 10.1007/s11192-009-0146-3 
EITEN, G. Classificação da vegetação do Brasil. Brasília: CNPq, 1983.

ERASMI, S.; SCHUCKNECHT, A.; BARBOSA, M. P.; MATSCHULLAT, J. Vegetation greenness in northeastern Brazil and its relation to ENSO warm events. Remote Sensing, v. 6, n. 4, p. 3041-3058, 2014. DOI. 10.3390/rs6043041

EVA, H. D.; MIRANDA, E. E.; DI BELLA, C. M.; GOND, V.; HUBER, O.; SGRENZAROLLI, M. et al. A Vegetation Map of South America - GLC 2000: Global Land Cover mapping for the year 2000. 2002.

FERNANDES, M. F.; QUEIROZ, L. P. Vegetação e flora da Caatinga. Ciência e Cultura, v. 70, p. 51-56, 2018. DOI. 10.21800/2317-66602018000400014

FREITAS, R. M.; ARAI, E.; ADAMI, M.; FERREIRA, A. S.; SATO, F. Y.; SHIMABUKURO, Y. E.; ROSA, R. R.; ANDERSON, L. O.; RUDORFF, B. F. T. Virtual laboratory of remote sensing time series: visualization of MODIS EVI2 data set over South America. Journal of Computational Interdisciplinary Sciences, v. 2, n. 1, p. 57-68, 2011. DOI. 10.6062/jcis.2011.02.01.0032

FUNDO AMAZÔNIA. Monitoramento Ambiental dos Biomas Brasileiros. Disponível em: < http://www.fundoamazonia.gov.br/pt/projeto/Monitoramento-Ambiental-dos-Biomas-Brasileiros/> . Acesso em: 18 jun. 2020.

GANEM, R. S. Caatinga: estratégias de conservação. Brasília: Câmara dos Deputados, Consultoria Legislativa, p. 105, 2017.

GIULIETTI, A. M.; NETA, A. L. DU B.; CASTRO, A. A. J. F.; et al. Diagnóstico da Vegetação Nativa do bioma Caatinga. In: J. M. C. Tabarelli; M. T. Fonseca; L. V. Lins (Orgs.); Biodiversidade da caatinga: áreas e ações prioritárias para a conservação. Brasília: Ministério do Meio Ambiente, p.382, 2004.

GORELICK, N.; HANCHER, M.; DIXON, M.; ILYUSHCHENKO, S.; THAU, D.; MOORE, R. Google Earth Engine: Planetary-scale geospatial analysis for everyone. Remote Sensing of Environment, 2017. DOI. 10.1016/j.rse.2017.06.031

HANSEN, M. C.; POTAPOV, P. V.; MOORE, R.; HANCHER, M.; TURUBANOVA, S. A.; TYUKAVINA, A.; THAU, D.; STEHMAN, S. V.; GOETZ, S. J.; LOVELAND, T. R.; KOMMAREDDY, A., et al. Highresolution global maps of 21 st-century forest cover change. Science, v. 342, n. 6160, p. 850-853, 2013. DOI. 10.1126/science. 1244693

INSTITUTO BRASILEIRO DE GEOGRAFIA E ESTATÍSTICA (IBGE). Desbravar, conhecer, mapear: memórias do Projeto Radam/RadamBrasil. Rio de Janeiro: IBGE, 2018.

INSTITUTO BRASILEIRO DE GEOGRAFIA E ESTATÍSTICA (IBGE). Biomas e sistema costeirocarinho do Brasil: compatível com a escala 1:250. 000. Rio de Janeiro: IBGE, 2019.

INSTITUTO BRASILEIRO DE GEOGRAFIA E ESTATÍSTICA (IBGE). Manual Técnico da Vegetação Brasileira. Rio de Janeiro: IBGE, 2012.

INSTITUTO CHICO MENDES DE CONSERVAÇÃO DA BIODIVERSIDADE (ICMBIO). Unidades de Conservação por bioma. Brasília: ICMBio, 2019.

INSTITUTO NACIONAL DE PESQUISAS ESPACIAIS (INPE). Brazil Data Cube. Disponível em: <brazildatacube.org>. Acesso em: 25 jul. 2020.

LAI, P.; ZHANG, M.; GE, Z.; HAO, B.; SONG, Z.; HUANG, J.; MA, M.; YANG, H.; HAN, X. Responses of seasonal indicators to extreme droughts in Southwest China. Remote Sensing, v. 12, n. 5, 2020. DOI. $10.3390 / \mathrm{rs} 12050818$

LAMBIN, E. F.; GEIST, H. J.; LEPERS, E. Dynamics of land-use and land-cover change in tropical regions. Annual Review of Environment and Resources, v. 28, p. 205-241, 2003. DOI. 10.1146/annurev.energy.28.050302.105459

LEAL, I. R.; DA SILVA, J. M.; TABARELLI, M.; LACHER JR., T. . Mudando o curso da conservação da biodiversidade na Caatinga do Nordeste do Brasil. Megadiversidade, v. 1, n. 1, p. 8, 2005.

LEAL, I. R.; TABARELLI, M.; SILVA, J. M. C. Ecologia e conservação da Caatinga: uma introdução ao desafio. Ecologia e conservação da caatinga. Recife: Editora Universitária UFPE, 2003. 
LIMA, A. L. A.; RODAL, M. J. N. Phenology and wood density of plants growing in the semi-arid region of northeastern Brazil. Journal of Arid Environments, v. 74, n. 11, p. 1363-1373, 2010. DOI. 10.1016/j.jaridenv.2010.05.009

LOVELAND, T. R.; DWYER, J. L. Landsat: Building a strong future. Remote Sensing of Environment, v. 122, p.22-29, 2012. DOI. 10.1016/j.rse.2011.09.022

MALDONADO, F. D.; SANTOS, J. R.; CARVALHO, V. C. Land use dynamics in the semi-arid region of Brazil (Quixaba, PE): Characterization by principal component analysis (PCA). International Journal of Remote Sensing, v. 23, n. 23, p. 5005-5013, 2002. DOI. 10.1080/0143116021000013313

MAPBIOMAS. Coleção 4.1 da Série Anual de Mapas de Cobertura e Uso do Solo do Brasil. Disponível em: <mapbiomas.org.>. Acesso em: 25 jun. 2020.

MAPBIOMAS ÁRIDAS. Sistema de Monitoramento da Degradação e Recuperação da Terra. Disponível em: <aridas.mapbiomas.org>. Acesso em: 30 out. 2020.

MARENGO, J. A. Mudanças Climáticas e Eventos Extremos no Brasil. Rio de Janeiro: FBDS, 2009.

MARENGO, J. A.; TORRES, R. R.; ALVES, L. M. Drought in Northeast Brazil—past, present, and future. Theoretical and Applied Climatology, v. 129, n. 3-4, p. 1189-1200, 2017. DOI. 10.1007/s00704-016$1840-8$

MAYES, M. T.; MUSTARD, J. F.; MELILLO, J. M. Forest cover change in Miombo Woodlands: modeling land cover of African dry tropical forests with linear spectral mixture analysis. Remote Sensing of Environment, v. 165, p. 203-215, 2015. DOI. 10.0.3.248/j.rse.2015.05.006

MIRANDA, R. Q.; NÓBREGA, R. L. B.; MOURA, M. S. B. DE; RAGHAVAN, S.; GALVÍNCIO, J. D. Realistic and simplified models of plant and leaf area indices for a seasonally dry tropical forest. International Journal of Applied Earth Observation and Geoinformation, v. 85, p. 101992, 2020. DOI. 10.1016/j.jag.2019.101992

MINISTÉRIO DO MEIO AMBIENTE (MMA)/ INSTITUTO BRASILEIRO DO MEIO AMBIENTE E DOS RECURSOS NATURAIS RENOVÁVEIS (IBAMA). Monitoramento do desmatamento dos biomas brasileiros por satélite - monitoramento do bioma caatinga. Brasília: MMA, p. 46, 2011.

MINISTÉRIO DO MEIO AMBIENTE (MMA). PROBIO - Levantamento da cobertura vegetal do uso do solo do bioma Caatinga. Brasília: MMA, 2006.

MINISTÉRIO DO MEIO AMBIENTE (MMA). Mapas de Cobertura Vegetal dos Biomas Brasileiros. Disponível em: <https://www.mma.gov.br/informma/item/7626-mapas-de-cobertura-vegetal.html>. Acesso em: 15 jun. 2020.

MONGE, R. A.; MARCO, F. S.; CERVIGON, F. T. An Assessment of the Consistency for Software Measurement Methods. CoRR, cs.SE/0204014, p. 1-7, 2002.

MORO, M. F.; NIC LUGHADHA, E.; ARAÚJO, F. S.; MARTINS, F. R. A Phytogeographical Metaanalysis of the Semiarid Caatinga Domain in Brazil. Botanical Review, v. 82, n. 2, p. 91-148, 2016. DOI. 10.1007/s12229-016-9164-Z

NAGLER, P. L.; DAUGHTRY, C. S. T.; GOWARD, S. N. Plant litter and soil reflectance. Remote Sensing of Environment, v. 71, n. 2, p. 207-215, 2000. DOI. 10.1016/S0034-4257(99)00082-6

OLOFSSON, P.; FOODY, G. M.; HEROLD, M.; STEHMAN, S. V.; WOODCOCK, C. E.; WULDER, M. A. Good practices for estimating area and assessing accuracy of land change. Remote Sensing of Environment, v. 148, p. 42-57, 2014. DOI. 10.1016/j.rse.2014.02.015

PAREYN, F. G. C. A importância da produção não-madeireira na Caatinga. In: M. A. Gariglio; E. V. de S. B. Sampaio; L. A. Cestaro; P. Y. Kageyama (Orgs.); Uso sustentável e conservação dos recursos florestais da caatinga. p.99-113. Brasília: Serviço Florestal Brasileiro, 2010

PEREIRA, I. M.; ANDRADE, L. A.; SAMPAIO, E. V. S. B.; BARBOSA, M. R. V. Use-history Effects on Structure and Flora of Caatinga. Biotropica, v. 35, n. 2, p. 154-165, 2003. DOI. 10.1111/j.17447429.2003.tb00275.x 
QI, M.; LIU, S.; YAO, X.; XIE, F.; GAO, Y. Monitoring the ice phenology of Qinghai lake from 1980 to 2018 using multisource remote sensing data and Google Earth Engine. Remote Sensing, v. 12, n. 14, 2020. DOI. 10.3390/rs12142217

RASI, R.; BEUCHLE, R.; BODART, C.; VOLLMAR, M.; SELIGER, R.; ACHARD, F. Automatic Updating of an Object-Based Tropical Forest Cover Classification and Change Assessment. IEEE Journal of Selected Topics in Applied Earth Observations and Remote Sensing, v. 6, n. 1, p. 66-73, 2013. DOI. 10.1109/JSTARS.2012.2217733

RAŠI, R.; BODART, C.; STIBIG, H.-J.; EVA, H.; BEUCHLE, R.; CARBONI, S.; SIMONETTI, D.; ACHARD, F. An automated approach for segmenting and classifying a large sample of multi-date Landsat imagery for pan-tropical forest monitoring. Remote Sensing of Environment, v. 115, n. 12, p. 36593669, 2011. DOI. 10.016/j.rse.2011.09.004

REDO, D.; AIDE, T. M.; CLARK, M. L. Vegetation change in Brazil's dryland ecoregions and the relationship to crop production and environmental factors: Cerrado, Caatinga, and Mato Grosso, 2001-2009. Journal of Land Use Science, v. 8, n. 2, p. 123-153, 2013. DOI. 10.1080/1747423X.2012.667448

RIBEIRO, E. M. S.; SANTOS, B. A.; ARROYO-RODRÍGUEZ, V.; TABARELLI, M.; SOUZA, G.; LEAL, I. R. Phylogenetic impoverishment of plant communities following chronic human disturbances in the Brazilian Caatinga. Ecology, v. 97, n. 6, p. 1583-1592, 2016. DOI. 10.1890/15-1122.1

RICHARDSON, A. D.; BRASWELL, B. H. .; HOLLINGER, D. Y. .; JENKINS, J. P.; OLLINGER, S. V. Near-surface remote sensing of spatial and temporal variation. Ecological Applications, v. 19, n. 6, p. 1417-1428, 2009. DOI. 10.1890/08-2022.1

RODAL, M. J. N.; BARBOSA, M. R. V; THOMAS, W. W. Do the seasonal forests in northeastern Brazil represent a single floristic unit? Brazilian Journal of Biology, v. 68, p. 467-475, 2008. DOI. 10.1590/S1519-69842008000300003

SANTOS, J. M.; PESSOA, M. M. D. L.; FERREIRA, R. L. C.; SILVA, E. A. Land-use and coverage in the structure of the landscape in a Tropical Dry Forest in northeast Brazil. Journal of Environmental Analysis and Progress, v. 5, n. 1, p. 088, 2020. DOI. 10.24221/jeap.5.1.2020.2675.088-097

SANTOS, J. C.; LEAL, I. R.; ALMEIDA-CORTEZ, J. S.; FERNANDES, G. W.; TABARELLI, M. Caatinga: The scientific negligence experienced by a dry tropical forest. Tropical Conservation Science, v. 4, n. 3, p. 276-286, 2011. DOI. 10.1177/194008291100400306

SANTOS, R. M.; OLIVEIRA-FILHO, A. T.; EISENLOHR, P. V.; QUEIROZ, L. P.; CARDOSO, D. B. O. S.; RODAL, M. J. N. Identity and relationships of the Arboreal Caatinga among other floristic units of seasonally dry tropical forests (SDTFs) of north-eastern and Central Brazil. Ecology and Evolution, v. 2, n. 2, p. 409-428, 2012. DOI. 10.1002/ece3.91

SESTINI, M. F.; ALVALÁ, R. C. S.; MELlO, E. M. K.; VAlERIANO, D. M.; CHAN, C. S.; NOBRE, C. A.l PAIVA, J. A. C.; REIMER, E. S. Elaboração de mapas de vegetação para utilização em modelos meteorológicos e hidrológicos. INPE: São José dos Campos, 2002.

ShIMABUKURO, Y. E.; ARAI, E.; DUARTE, V.; DUTRA, A. C.; CASSOL, H. L. G.; SANO, E. E.; HOFFMANN, T. B. Discriminating Land Use and Land Cover Classes in Brazil Based on the Annual PROBA-V 100 m Time Series. IEEE Journal of Selected Topics in Applied Earth Observations and Remote Sensing, v. 13, p. 3409-3420, 2020. DOI. 10.1109/JSTARS.2020.2994893

SIDHU, N.; PEBESMA, E.; CÂMARA, G. Using Google Earth Engine to detect land cover change: Singapore as a use case. European Journal of Remote Sensing, v. 51, n. 1, p. 486-500, 2018. DOI. 10.1080/22797254.2018.1451782

SILVEIRA, E. M. O.; ESPÍRITO-SANTO, F. D. B.; ACERBI-JÚNIOR, F. W.; GALVÃO, L. S.; WITHEY, K. D.; BLACKBURN, G. A.; MELLO, J. M.; SHIMABUKURO, Y. E.; DOMINGUES, T.; SCOLFORO, J. R. S. Reducing the effects of vegetation phenology on change detection in tropical seasonal biomes. GIScience \& Remote Sensing, v. 56, n. 5, p. 699-717, 2019. DOI. 10.1080/15481603.2018.1550245

SILVEIRA, H. L. F.; GALVÃO, L. S.; SANCHES, I. D.; SÁ, I. B.; TAURA, T. A. Use of MSI/Sentinel-2 and 
airborne LiDAR data for mapping vegetation and studying the relationships with soil attributes in the Brazilian semi-arid region. International Journal of Applied Earth Observation and Geoinformation, v. 73, p. 179-190, 2018. DOI. 10.1016/j.jag.2018.06.016

SOBRINHO, M. S.; TABARELLI, M.; MACHADO, I. C.; SFAIR, J. C.; BRUNA, E. M.; LOPES, A. V. Land use, fallow period and the recovery of a Caatinga forest. Biotropica, v. 48, n. 5, p. 586-597, 2016. DOI. 10.1111/btp.12334

SONNENTAG, O.; HUFKENS, K.; TESHERA-STERNE, C.; YOUNG, A. M.; FRIEDL, M., et. al. Digital repeat photography for phenological research in forest ecosystems. Agricultural and Forest Meteorology, v. 152, n. 1, p. 159-177, 2012. DOI. 10.1016/j.agrformet.2011.09.009

STEHMAN, S. V. Sampling designs for accuracy assessment of land cover. International Journal of Remote Sensing, v. 30, n. 20, p. 5243-5272, 2009. DOI. 10.1080/01431160903131000

STEHMAN, S. V. Estimating area and map accuracy for stratified random sampling when the strata are different from the map classes. International Journal of Remote Sensing, v. 35, n. 13, p. 4923-4939, 2014. DOI. 10.1080/01431161.2014.930207

STERCKX, S.; BENHADJ, I.; DUHOUX, G.; LIVENS, S.; DIERCKX, W.; GOOR, E.; ADRIAENSEN, S.; HEYNS, W.; VAN HOOF, K. et al. The PROBA-V mission: image processing and calibration. International Journal of Remote Sensing, v. 35, n. 7, p. 2565-2588, 2014. DOI. 10.1080/01431161.2014.883094

STROPPIANA, D.; BORDOGNA, G.; CARRARA, P.; BOSCHETTI, M.; BOSCHETTI, L.; BRIVIO, P. A. A method for extracting burned areas from Landsat TM/ETM+ images by soft aggregation of multiple Spectral Indices and a region growing algorithm. ISPRS Journal of Photogrammetry and Remote Sensing, v. 69, p. 88-102, 2012. DOI. 10.1016/j.isprsjprs.2012.03.001

TOMASEllA, J.; VIEIRA, R. M. S. P.; BARBOSA, A. A.; RODRIGUEZ, D. A.; SANTANA, M. O.; SESTINI, M. F. Desertification trends in the Northeast of Brazil over the period 2000-2016. International Journal of Applied Earth Observation and Geoinformation, v. 73, p. 197-206, 2018. DOI. 10.1016/j.jag.2018.06.012

Velloso, A. L.; SAMPAIO, E. V. S. .; PAREYN, F. G. C. Ecorregiões: Propostas para o bioma Caatinga. Resultados do Seminário de Planejamento Ecorregional da Caatinga/Aldeia-PE. Recife: APNE/ICA/TNC, 2002.

VELOSO, H. P.; GÓES FILHO, L. Fitogeografia brasileira: classificação fisionômico-ecológica da vegetação neotropical. Salvador: IBGE, 1982.

VIEIRA, R. M. S. P.; CUNHA, A. P. M. A.; ALVALÁ, R. C. S.; ALVALÁ, R. C. S.; et al. Land Use and Land Cover Map of a Semiarid Region of Brazil for Meteorological and Climatic Models. Revista Brasileira de Meteorologia, v. 28, n. 2, p. 129-138, 2013. DOI. 10.1590/S0102-77862013000200002

VIEIRA, R. M. S. P.; TOMASELLA, J.; ALVALÁ, R. C. S.; SESTINI, M. F. et al. Identifying areas susceptible to desertification in the Brazilian northeast. Solid Earth, v. 6, n. 1, p. 347-360, 2015. DOI. 10.5194/se-6-347-2015

WAN, Z.; ZHANG, Y.; ZHANG, Q.; LI, Z.-L. Quality assessment and validation of the MODIS global land surface temperature. International Journal of Remote Sensing, v. 25, n. 1, p. 261-274, 2004. DOI. $10.1080 / 0143116031000116417$

XUE, Y.; SELLERS, P. J.; KINTER, J. L.; SHUKLA, J. A Simplified Biosphere Model for Global Climate Studies. Journal of Climate, v. 4, n. 3, p. 345-364, 1991. DOI. 10.1175/1520-0442(1991)004<0345:A SBMFG> . 


\section{Biografias dos autores}
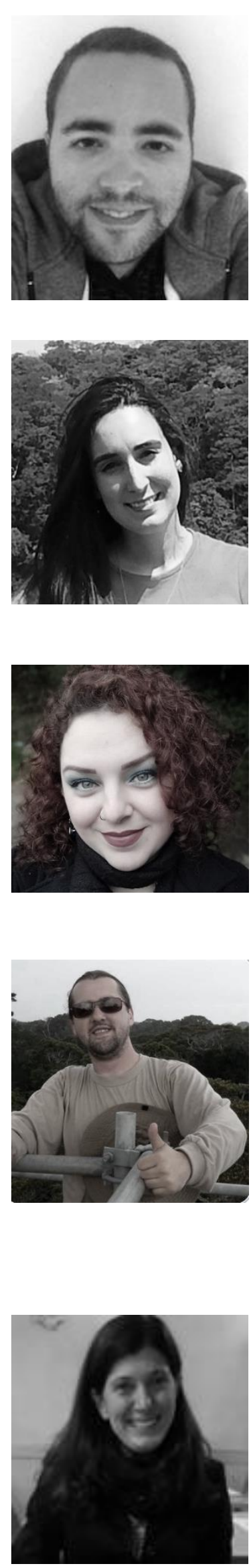

Khalil Ali Ganem nasceu no estado de Goiás e possui os títulos de Bacharel em Ciências Ambientais e Mestre em Geociências Aplicadas, ambos pela Universidade de Brasília (UnB). Possui experiência com mapeamento e monitoramento da vegetação usando técnicas de sensoriamento remoto, bem como na interpretação e coleta de dados para validação de mapas globais em diferentes ecossistemas da América do Sul. Atualmente é bolsista (PCI/CNPq) no Instituto Nacional de Pesquisas Espaciais (INPE) e seus interesses de pesquisa são no uso do sensoriamento remoto para investigar mudanças de uso e cobertura da terra, ciclo do carbono e comportamento sazonal da vegetação.

Andeise Cerqueira Dutra nasceu na Bahia. Recebeu o BSc em Engenharia Florestal pela Universidade Federal do Recôncavo da Bahia (UFRB) em 2017 e o MSc em Sensoriamento Remoto pelo Instituto Nacional de Pesquisas Espaciais (INPE) em 2019. Idealizou e concebeu o projeto de mapeamento e monitoramento do Nordeste Brasileiro (Conselho Nacional de Desenvolvimento Científico e Tecnológico CNPq, 431172/2018-8). Atualmente é bolsista no projeto de Sistema de Risco de Incêndio no Bioma Cerrado (SIRI, CNPq/Prefvogo). Seus interesses de pesquisa são fenologia das espécies, mudanças de uso e cobertura da terra, e monitoramento da vegetação utilizando técnicas de sensoriamento remoto.

Marceli Terra nasceu no interior de São Paulo (1989). Recebeu o BSc em Ciências Ambientais (2014) e o MSc em Geociências Aplicadas (2017), ambos pela Universidade de Brasília (UnB). Atualmente realiza o $\mathrm{PhD}$ em Sensoriamento Remoto no Instituto Nacional de Pesquisas Espaciais (INPE) com estudo das fitofisionomias do Cerrado. Seus interesses de pesquisa são no uso de sensoriamento remoto e sistema de informações geográficas (SIG) para o monitoramento da vegetação, mudanças ambientais e na conservação do bioma Cerrado.

Ramon Morais de Freitas, natural de Barbacena-MG, possui graduação em Ciências Aeronáuticas (2004), mestrado em Sensoriamento Remoto (2007) e doutorado em Computação Aplicada pelo Instituto Nacional de Pesquisas Espaciais (2012). Ele é especialista em análise e visualização de dados de sensoriamento remoto, incluindo processamento de imagens, análise espacial, reconhecimento de padrões, análise de séries temporais e computação científica. É pesquisador associado na Camargo-Schubert conduzindo projetos de P\&D na área eólica e solar. Em 2012, venceu o prêmio Marechal-do-Ar Casimiro Montenegro Filho promovido pela Secretaria de Assuntos Estratégicos da Presidência da República pela melhor tese de doutorado na categoria aeroespacial.

Rosana C. Grecchi nasceu no Estado de São Paulo. Possui graduação em Geologia pela Universidade Estadual Paulista (UNESP), mestrado em Geotecnia pela Universidade de São Paulo (USP), doutorado em Sensoriamento Remoto pela Universidade de Sherbrooke (Canadá) e pós-doutorado pelo Instituto Nacional de Pesquisas Espaciais (INPE). Suas áreas de experiência incluem o uso de sensoriamento remoto e sistema de informações geográficas para análise de mudanças de uso e cobertura da terra em alguns biomas brasileiros. Atualmente trabalha para Arcadia SIT (Itália) como consultora externa no JRC em projetos relacionados a incêndios florestais. 

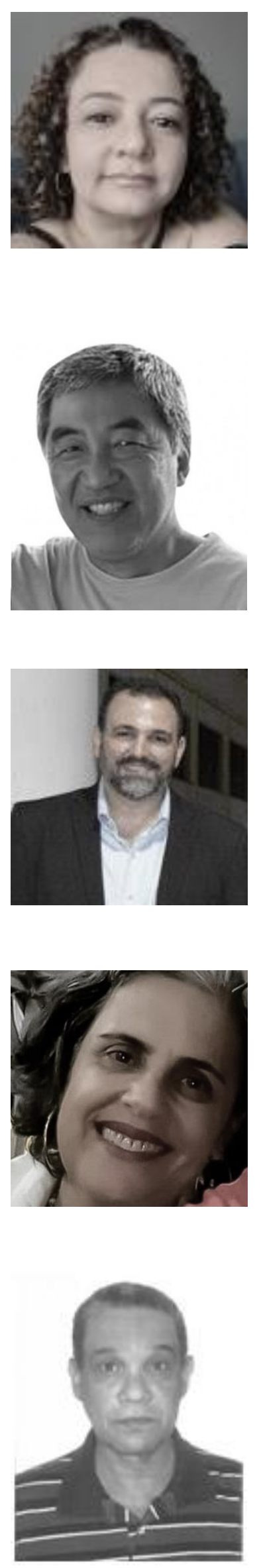

Rita Vieira nasceu em Ubatuba em 21 de março de 1972. Possui graduação em Biologia pela Universidade de Taubaté (UNITAU), mestrado em Sensoriamento Remoto e doutorado em Ciências do Sistema Terrestre, ambos pelo Instituto Nacional de Pesquisas Espaciais (INPE). Atualmente trabalha no INPE com estudos focados na Mudança da Cobertura do Uso do Solo e sua influência na degradação/desertificação do solo nos biomas Caatinga e Cerrado, sendo o trabalho mais recente "Avaliação de risco de desertificação no Nordeste do Brasil: Tendências atuais e cenários futuros". Revista Land Degradation \& Development, 2020 .

Egidio Arai recebeu o título de Tecnólogo em Processamento de Dados pela Universidade de Taubaté (UNITAU), em 1986, Mestre em Computação Aplicada, em 2002, e Doutor em Sensoriamento Remoto, em 2011, pelo Instituto Nacional de Pesquisas Espaciais (INPE), São José dos Campos, Brasil. Atualmente é Tecnologista Sênior no INPE. Seus interesses são ciência da computação e sensoriamento remoto, atuando nos seguintes assuntos: processamento de imagens, séries temporais de imagens, ecossistemas tropicais e ciências ambientais, recursos florestais e sistemas de computador.

Fabrício Brito é Engenheiro Agrônomo pela Universidade Estadual do Maranhão (2005), Mestre em Agronomia pela Universidade Federal do Piauí (2008) e Doutor em Sensoriamento Remoto pelo Instituto Nacional de Pesquisas Espaciais (2013). Atualmente, é pesquisador do Programa de Pós-Graduação em Meio Ambiente da Universidade CEUMA. Seus interesses de pesquisa são na área de modelagem ambiental com ênfase nas interações entre homem, natureza, clima, saúde e sociedade.

Claudia Sampaio nasceu em Salvador, Bahia, em 1966. Possui graduação em Agronomia (1987), mestrado em Ciências Agrárias (1995), ambos pela Universidade Federal da Bahia (1987), e doutorado em Água e Solo pela Faculdade de Engenharia Agrícola/UNICAMP (2006). Atualmente é Professora Associada IV do Centro de Ciências Exatas e Tecnológicas da Universidade Federal do Recôncavo da Bahia. Seus interesses de pesquisa são geoprocessamento, sensoriamento remoto, degradação ambiental, recuperação de áreas degradadas, bacias hidrográficas e aptidão de terras.

Valdete Duarte nasceu em 1963, se formou em Agronomia (1977) pela Universidade Federal de Viçosa (UFV) e recebeu o título de Mestre (1980) em Sensoriamento Remoto pelo Instituto Nacional de Pesquisas Espaciais (INPE), de São José dos Campos, onde trabalha desde 1978. Ao longo dos últimos 40 anos, no INPE, tem atuado em pesquisas sobre a Amazônia brasileira nos projetos PRODES Analógico, PRODES Digital, DETER e PANAMAZÔNIA I. A evolução desses projetos levou ao PANAMAZÔNIA II, projeto que visa monitorar toda a floresta tropical na região Amazônica da América do Sul, com foco também no mapeamento de áreas desmatadas, cicatrizes de queimadas e regeneração da vegetação, além do mapeamento da hidrografia da América do Sul. 


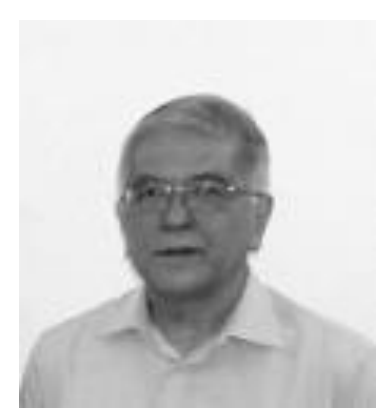

Yosio Edemir Shimabukuro recebeu o BSc em Engenharia Florestal pela Universidade Federal Rural do Rio de Janeiro (UFRRJ) em 1972; MSc em Sensoriamento Remoto pelo Instituto Nacional de Pesquisas Espaciais (INPE) em 1977; e PhD pela Colorado State University - EUA em 1987. De janeiro de 1992 a março de 1994, foi pesquisador visitante no Goddard Space Flight Center da NASA, EUA. Desde 1973, está no INPE, utilizando dados de sensoriamento remoto por satélite e terrestre para análise de cobertura vegetal. Vem aplicando técnicas e modelos de sistema de informação geográfica e sensoriamento remoto para detecção de mudanças ambientais em diferentes biomas do Brasil. É pesquisador $1 \mathrm{~A}$ do Conselho Nacional de Desenvolvimento Científico e Tecnológico CNPq. devido crédito pela criação original. 